\title{
Vibration serviceability assessment of office floors for realistic walking and floor layout scenarios: Literature review
}

\begin{tabular}{|c|c|}
\hline Journal: & Advances in Structural Engineering \\
\hline Manuscript ID & ASE-18-0508.R3 \\
\hline Manuscript Type: & Review \\
\hline $\begin{array}{r}\text { Date Submitted by the } \\
\text { Author: }\end{array}$ & $n / a$ \\
\hline Complete List of Authors: & $\begin{array}{l}\text { Goncalves, Marcio; University of Exeter College of Engineering } \\
\text { Mathematics and Physical Sciences } \\
\text { Pavic, A; University of Exeter College of Engineering Mathematics and } \\
\text { Physical Sciences } \\
\text { Pimentel, Roberto; Universidade Federal da Paraiba, Departamento de } \\
\text { Engenharia Civil e Ambiental }\end{array}$ \\
\hline Keywords: & $\begin{array}{l}\text { Vibration, floors, office layout, human-structure interaction, multi-person } \\
\text { walking, vibration dose values }\end{array}$ \\
\hline Abstract: & $\begin{array}{l}\text { Over the last two decades, office floors have been built progressively } \\
\text { lightweight with increasing spans and slenderness. Therefore, vibration } \\
\text { performance of office floors due to walking dynamic loads is becoming } \\
\text { their governing design criterion, determining their size and shape, and } \\
\text { therefore overall weight and embodied energy of the building. To date, } \\
\text { floor design guidelines around the world recommend walking load } \\
\text { scenarios in offices featuring some or all of the following standard } \\
\text { characteristics: (a) walking loads are assumed to be periodic dynamic } \\
\text { excitation represented by the Fourier series, including harmonics } \\
\text { corresponding to up to the first four integer multiples of the pacing } \\
\text { frequency of which at least one is exciting the floor at a resonant } \\
\text { frequency and (b) single person walking. However, the literature } \\
\text { surveyed provides evidence that such assessment methodology is } \\
\text { potentially an over-simplification which as it does not reflect real walking } \\
\text { load scenarios, since crucial features of the floor vibration source, path } \\
\text { and receiver are missing. First, in terms of vibration source realistic } \\
\text { scenarios need to feature: (a) moving rather than stationary walking } \\
\text { forces; (b) stochastic nature of human gait; (c) simultaneous multi- } \\
\text { person walking; and (d) human-structure interaction. Second, for the } \\
\text { transmission path (i.e. office floor structure), two features are needed to } \\
\text { consider: (a) realistic office floor layouts and (b) presence, or absence, } \\
\text { of non-structural elements. Finally, for the vibration receivers (i.e. floor } \\
\text { occupants): (a) vibrations calculated at floor locations occupied by users } \\
\text { (instead of at the potential highest response location which may not be } \\
\text { occupied); (b) actual period over which occupants feel vibration due to } \\
\text { such excitation and (c) assessment of vibration levels based on their } \\
\text { probability of occurrence. This paper therefore addresses these seldom } \\
\text { considered but increasingly important features and discusses realistic } \\
\text { approaches to floor design for vibration serviceability. }\end{array}$ \\
\hline
\end{tabular}




\section{SCHOLARONE $^{\mathrm{M}}$ Manuscripts}




\title{
1 Introduction
}

\author{
Vibration serviceability of office floors under footfall-induced dynamic \\ excitation during walking is becoming their governing design criterion in modern \\ buildings.
}

This is explained by the fact that, during the last two decades, floors have been built with longer spans, lower floor thickness, and high strength lightweight materials (e.g. composite steel-lightweight floors supported by steel frames), employing innovative construction techniques. Modern architectural trends include slender and 'transparent' structures, and the prioritisation of spacious and airy open-plan working environments. Such modifications have led to a reduction of the first natural frequency (or fundamental frequency, $f_{1}$ ) and modal damping ratios $\left(\zeta_{n} ; n\right.$ is the mode number), coupled with generally lower mass. Floors with mass of $150 \mathrm{~kg} / \mathrm{m}^{2}$ or less are becoming more and more common. In addition, modern offices are typically low-frequency floors (Reynolds and Pavic, 2003), i.e. floors with fundamental natural frequency up to $10 \mathrm{~Hz}$, for vertical vibration, which may experience near-resonant walking-induced vibrations. The combination of these developments has resulted in office floors experiencing excessive vertical vibrations more frequently in the last five years than previously. For example, the unpublished results of the survey of structural design practitioners, carried out in 2015 by the Institution of Structural Engineers (IStructE), 
which were made available to the second author, indicate that: (a) a quarter of respondents experienced problems with human perception of excessive vibrations in code-compliant structures, (b) a half would like to have more advanced design guidance for vibrations when designing steel (including composite) structures and (c) a quarter experienced problems with spans over $10 \mathrm{~m}$, which are becoming common in open-plan office design nowadays.

Moreover, three important facts related to vibration serviceability specifically of office floors can be observed in modern design practice and throughout the surveyed literature.

Firstly, office floors are widespread in urban environments . For example, more than 1.1 million square meters of office space were built in the United Kingdom every year of the last decade. This is an asset portfolio worth $£ 5$ bn (the highest of all commercial property sub-sectors) according to the Property Data Report (Property Industry Alliance, 2017). However, up to $20 \%$ extra costs due to structural modifications of slabs, beams and curtain walls can be added to overall building construction budgets to meet adequate vibration performance (Hanagan and Chattoraj, 2006). This is even higher when modifications in columns and foundations to satisfy floor vibration serviceability are considered.

Secondly, in the context of excessive walking-induced vibrations in buildings, office floors are especially relevant for the following reasons: 
1. An increasing number of case studies of excessive walking-induced vibrations in office floors have been reported in the literature.

2. Remedial measures to attenuate excessive floor vibrations are costly and very difficult to carry out post-construction.

3. Out of court settlements and litigation related to vibration serviceability of building floors are increasingly frequent.

4. There is a lack of walking load scenarios for representing realistic in-service conditions of walking excitation over office floors, as appropriate when dealing with serviceability as opposed to ultimate limit state design.

5. Uncertainty in the modelling of realistic vibration serviceability scenarios is compensated by 'structural modifications' to control uncertain vibrations, which means increasing mass and stiffness of floor structure. These account for over $60 \%$ of the overall building mass in multi-storey buildings leading to wasteful design and usually large embodied energy in buildings.

Table 1 presents typical case studies of excessive vibrations in office floors. It should be noted that they are all considered low-frequency floors. Dozens of similar cases have been reported since the beginning of this century. 
Table 1. Case studies of excessive walking-induced floor vibrations. 
Table 1. Case studies of excessive walking-induced floor vibrations (continuation).

\begin{tabular}{|c|c|c|c|}
\hline Case \# & Dynamic properties & Floor System & Floor description \\
\hline 9 & $\begin{array}{l}\text { Fund. nat. freq.: } 6.40 \mathrm{~Hz} \\
\text { Damping ratio: } 3 \% . \\
\text { (Díaz and Reynolds, } \\
\text { 2010) }\end{array}$ & Steel-concrete composite. & $\begin{array}{l}\text {-Walking path: lateral corridors. } \\
\text { - Layout: open-plan; no partitions; } \\
\text { paperless. } \\
\text { - Floor panel dimensions: not available } \\
\text { (only total floor area of } 24 \text { x } 72 \mathrm{~m} \text { was } \\
\text { informed). }\end{array}$ \\
\hline 10 & $\begin{array}{l}\text { Fund. nat. freq.: } 5.60 \mathrm{~Hz} \\
\text { Damping ratio: } 2 \% . \\
\text { (Lindenberg and } \\
\text { Fraczek, 2013) }\end{array}$ & Precast concrete. & $\begin{array}{l}\text {-Walking path: not available. } \\
\text { - Layout: bare floor. } \\
\text { - Floor panel dimensions: bay of } 15.25 \\
\text { x } 14 \text { m. }\end{array}$ \\
\hline 11 & $\begin{array}{l}\text { Fund. nat. freq.: } 6.20 \mathrm{~Hz} \\
\text { Damping ratio: } 2.5-3 \% \text {. } \\
\text { (Nguyen et al., 2014) }\end{array}$ & Steel-concrete composite. & $\begin{array}{l}\text {-Walking path: two corridors crossing } \\
\text { centre bay. } \\
\text { - Layout: not available. } \\
\text { - Floor panel dimensions: not available. }\end{array}$ \\
\hline 12 & $\begin{array}{l}\text { Fund. nat. freq.: } 5.24 \mathrm{~Hz} \\
\text { Damping ratio: } 3.16 \% \\
\text { (Muhammad and } \\
\text { Reynolds, 2019) }\end{array}$ & Steel-concrete composite. & $\begin{array}{l}\text {-Walking path: path crossing three } \\
\text { panels adjacent to building perimeter. } \\
\text { - Layout: open-plan. } \\
\text { - Floor panel dimensions: } 13 \text { x } 9 \mathrm{~m} \text {. }\end{array}$ \\
\hline 13 & $\begin{array}{l}\text { Fund. nat. freq.: } 4.92 \mathrm{~Hz} \\
\text { Damping ratio: } 0.66 \% \\
\text { (Muhammad and } \\
\text { Reynolds, 2019) }\end{array}$ & Steel-concrete composite. & $\begin{array}{l}\text {-Walking path: path crossing five panels } \\
\text { adjacent to building perimeter. } \\
\text { - Layout: not informed. } \\
\text { - Floor panel dimensions: } 15 \text { × } 6.25 \mathrm{~m} \text {. }\end{array}$ \\
\hline 14 & $\begin{array}{l}\text { Fund. nat. freq.: } 6.56 \mathrm{~Hz} \\
\text { Damping ratio: } 1.0 \% \\
\text { (Muhammad and } \\
\text { Reynolds, 2019) }\end{array}$ & Steel-concrete composite. & $\begin{array}{l}\text {-Walking path: not available. } \\
\text { - Layout: fully furnished; multipurpose } \\
\text { building. } \\
\text { - Floor panel dimensions: } 9.75 \text { x } 6.1 \mathrm{~m} \text {. }\end{array}$ \\
\hline 15 & $\begin{array}{l}\text { Fund. nat. freq.: bays } \\
\text { with } f 1 \text { within } 4.5-6.5 \\
\text { Hz. } \\
\text { Damping ratio: not } \\
\text { available. } \\
\text { (Wong and Wesolowsky, } \\
\text { 2019) }\end{array}$ & Steel-concrete composite. & $\begin{array}{l}\text {-Walking path: not available. } \\
\text { - Layout: open-plan. } \\
\text { - Floor panel dimensions: } 9.15 \text { x } 9.15 \\
\text { m. }\end{array}$ \\
\hline 16 & $\begin{array}{l}\text { Fund. nat. freq.: } 4.0 \mathrm{~Hz} \text {. } \\
\text { Damping ratio: not } \\
\text { available. } \\
\text { (Wong and Wesolowsky, } \\
\text { 2019) }\end{array}$ & Steel-concrete composite. & $\begin{array}{l}\text {-Walking path: not available. } \\
\text { - Layout: not available. } \\
\text { - Floor panel dimensions: } 12.2 \text { x } 9.15 \\
\text { m. }\end{array}$ \\
\hline
\end{tabular}


Table 1. Case studies of excessive walking-induced floor vibrations (continuation).

\begin{tabular}{|c|c|c|c|}
\hline Case \# & Dynamic properties & Floor System & Floor description \\
\hline 17 & $\begin{array}{l}\text { Fund. nat. freq.: bays } \\
\text { with } f 1 \text { within } 5.0-6.3 \\
\text { Hz. } \\
\text { Damping ratio: not } \\
\text { available. } \\
\text { (Wong and Wesolowsky, } \\
2019 \text { ) }\end{array}$ & Steel-concrete composite. & $\begin{array}{l}\text {-Walking path: not available. } \\
\text { - Layout: not available. } \\
\text { - Floor panel dimensions: } 9.15 \text { x } 9.15 \\
\text { m. }\end{array}$ \\
\hline 18 & $\begin{array}{l}\text { Fund. nat. freq.: bays } \\
\text { with } f 1 \text { within } 5.7-6.3 \\
\text { Hz. } \\
\text { Damping ratio: not } \\
\text { available. } \\
\text { (Wong and Wesolowsky, } \\
\text { 2019) }\end{array}$ & Reinforced concrete. & $\begin{array}{l}\text {-Walking path: grid-like pattern around } \\
\text { the centre of the floor. } \\
\text { - Layout: not available. } \\
\text { - Floor panel dimensions: } 8 \times 8 \mathrm{~m} \text {. }\end{array}$ \\
\hline
\end{tabular}

Thirdly, current guidelines do not consider realistic walking load scenarios in office floor design for vibration serviceability. Realistic dynamic loading scenarios require knowledge of: (a) simultaneous multi-person walking, or SMPW (Živanović et al., 2012; Shahabpoor et al., 2017a); (b) human-structure interaction, or HSI (Brownjohn, 2001; Živanović, 2015; Shahabpoor et al., 2017a); (c) human-human interaction (HHI); (d) circulation patterns, such as the trajectories of walking followed by occupants (Mohammed and Pavic, 2017a); and (e) vibration calculation at points occupied by users, instead of at the highest response point which may not be occuppied (Varela, 2004; Shahabpoor et al., 2017a).

A critical review seeking for realistic approaches to walking load scenarios was carried out of the following design guidelines: 
1. Concrete Society Technical Report - Appendix G (Pavic and Willford, 2005).

2. Cement and concrete industry publication - CCIP-016 (Willford and Young, 2006).

3. ISO 10137 (2007).

4. HiVoSS - Research Fund for Coal \& Steel (RFCS, 2007)

5. SCI Publication No. P354 (Smith et al., 2009).

6. AISC Design Guide no. 11 (Murray et al., 2016).

7. Guideline "Steel construction: Floor vibration" (BCSA, 2016)

A crucial step for assessment of vibrations in structures is the rationalisation into and identification of the three key factors involved: (a) vibration source; (b) vibration transmission path; and (c) vibration receiver (ISO 10137, 2007). For vibrations in office floors, these key factors are walking excitation, floor structure, and human occupants, respectively. The guidelines are assessed for their provision against each of the three key factors.

This paper is organised into five sections. After this introduction, the second section describes the vibration source, where factors needed for modelling more realistic walking force are discussed. The third section is about the vibration transmission path (i.e. mass, stiffness and damping), where design of modern office floors for vibration serviceability is dealt with. The fourth section presents an overview of approaches for 
realistic assessment of floor vibration, focusing on human office occupants (i.e. the key receivers of such vibrations). Finally, the last section summarises the previous discussions, highlighting topics for future research. 


\section{Vibration source: walking excitation}

This section presents walking force models in the literature that represent the action of the walking occupant(s) in office floors. Also, the distribution of the walkinginduced dynamic loads over an office floor area, dictated by its layout, is discussed.

\subsection{Office floor walking load scenarios: background}

The guidelines AISC DG 11, CSTR 43 - AppG, CCIP-016, SCI P354 as well as the international standard ISO 10137 traditionally recommend the Fourier series walking force model (WFM) to check vibration serviceability of floors.

In the time domain, walking forces are assumed periodic and can be represented as a sum of harmonic components of the Fourier series (Bachmann et al., 1995), as shown in equation (1).

$$
F(t)=W\left\lceil\left(1+\sum_{n=1}^{N} \alpha_{n} \sin \left(2 \pi n f_{s} t+\varphi_{n}\right)\right\rceil\right.
$$

where $W$ is the persons' weight; $N$ is the number of harmonics considered; $f_{s}$ is the step frequency; $t$ is a time instant; $\varphi_{n}$ is the phase angle of harmonic $n\left(\varphi_{1}=0 ; \varphi_{2}=\varphi_{3}=\right.$ 
$\pi / 2$ ); and $\alpha_{n}$ is the dynamic load factor (or DLF, i.e. portion of the person's weight that acts dynamically in harmonic $n$ ).

Many different DLFs have been recommended in the literature, reflecting the natural intrasubject variability of human test subjects used in experiments to measure DLFs. Bachmann et al. (1995) recommended $\alpha_{1}=0.4 ; \alpha_{2}=\alpha_{3}=0.1$. The ISO 10137 proposed $\alpha_{1}=0.37\left(f_{s}-1.0\right) ; \alpha_{2}=0.1 ; \alpha_{3}=\alpha_{4}=0.06$. Finally, the CSTR 43 states design values $\alpha_{1}=0.41\left(f_{s}-0.95\right) ; \alpha_{2}=0.0056\left(f_{s}+12.3\right) ; \alpha_{3}=0.0064\left(f_{s}+5.2\right) ; \alpha_{4}=$ $0.0065\left(f_{s}+2.0\right)$, for a $25 \%$ probability of exceedance of such values in real walking. It is considered that walking-induced (near-)resonant response is possible for floors featuring fundamental natural frequency up to $10 \mathrm{~Hz}$ (low-frequency floors), as stated in design guidelines CSTR 43, CCIP-016, ISO 10137 and SCI P354. Since the maximum step frequency for normal walking does not exceed about $2.5 \mathrm{~Hz}$, only the first four harmonics of the walking frequency $(4 \times 2.5 \mathrm{~Hz}=10 \mathrm{~Hz})$, in equation 1 , are considered $(N=4)$.

Figure 1 shows a force time history of footfall forces generated by the Fourier series WFM. The sum of the four harmonic components yields the total periodic force. 


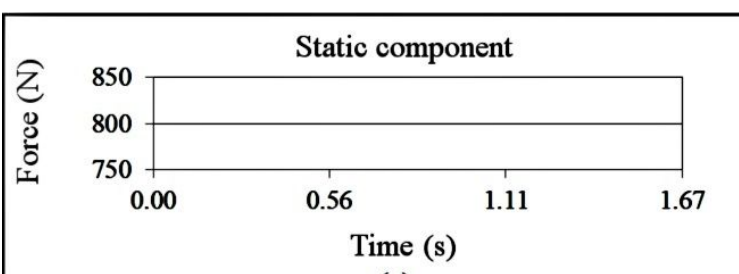

(a)

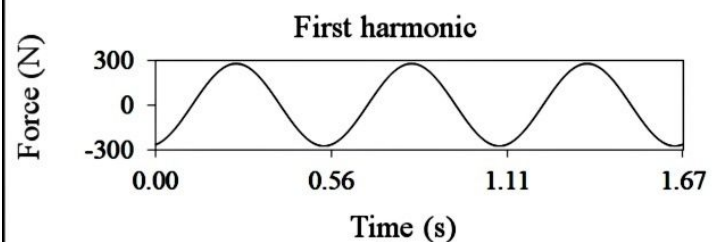

(b)

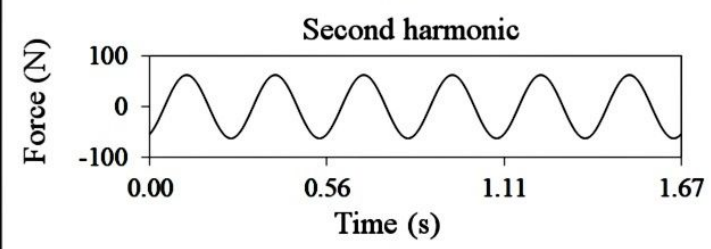

(c)

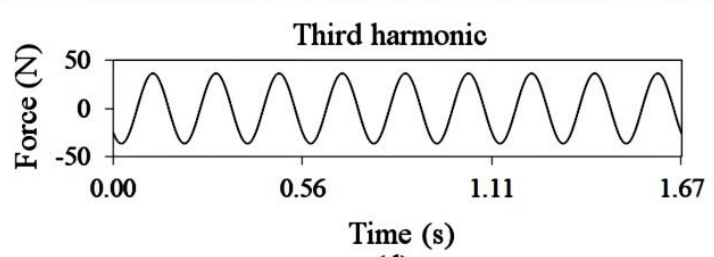

(d)

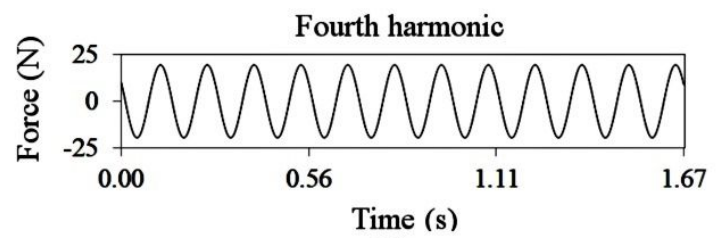

(e)

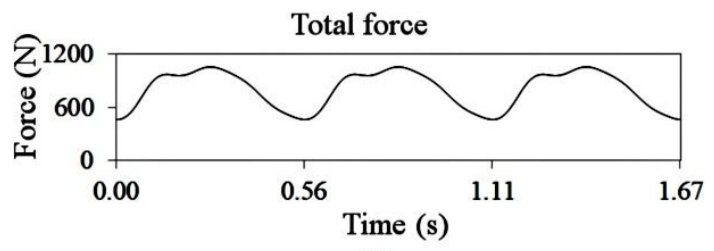

(f)

Figure 1. The first four harmonics and the total walking force (sum of harmonics), modelled by the Fourier series WFM, with walking frequency of $1.8 \mathrm{~Hz}$, person's weight of $800 \mathrm{~N}$, and phase angles $\varphi_{1}=$ $0 ; \varphi_{2}=\varphi_{3}=\varphi_{4}=\pi / 2$. DLFs are based on CSTR 43 (Pavic and Willford, 2005).

Wang and Chen (2017) compared walking-induced floor responses from 19 Fourier series walking force models (proposed between 1977 and 2014) and measured response (obtained from a single-person load scenario, i.e. one person crossing the structure) of a prototype concrete floor. Responses were measured and calculated at the centre of the floor. It was shown that significant underestimation and overestimation are possible when calculated vibration responses (using such models) and the measured responses are compared. The authors also stated that DLFs are the most important 
factors that drive different acceleration peak responses, often leading to conflicting assessment conclusions. Since some models overestimate and others underestimate the response when compared to field measurements, those authors concluded that it was difficult to select one best model from the ones investigated. On the other hand, for future developments of walking load models, they recommended the development of a test protocol. This makes sense in view of their findings, since experimental data is crucial to identify appropriate load models.

Modifications of the Fourier series WFM have been carried out to account for additional features of human walking, such as the inclusion of heel impact forces with higher frequency content. One example is the work of Varela (2004), who modelled heel impact forces, adding them to the Fourier series WFM to check the vibration serviceability of composite steel-concrete floors, as shown in equation (2).

$$
F(t)=\left\{\begin{array}{cc}
{\left[\frac{\left(f_{m i} F_{m}-W\right)}{(0.04 T)}\right] t+W} & \text { if } \\
f_{m i} F_{m}\left[\frac{C_{1}(t-0.04 T)}{0.02 T}+1\right] & \text { if } 0.04 T_{p} \leq t<0.06 T_{p} \\
F_{m} & \text { if } 0.06 T_{p} \leq t<0.15 T_{p} \\
W\left\{1+\sum_{n=1}^{N} \alpha_{n} \sin \left[2 \pi n f_{s}(t+0.1 T)+\varphi_{n}\right]\right\} & \text { if } 0.15 T_{p} \leq t<0.90 T_{p} \\
10\left(W-C_{2}\right)\left(\frac{t}{T}-1\right)+W & \text { if } 0.90 T_{p} \leq t<T_{p}
\end{array}\right.
$$


where, $f_{m i}$ is the heel-impact factor (i.e. the ratio between the peak magnitude of the heel-impact force and the maximum force generated by the Fourier series only) and $T_{P}$ is the duration of the step. From correlations of results from vibration tests of SPW and SMPW scenarios over a prototype concrete slab and numerical simulations, Varela (2004) obtained $f_{m i}=1.12$ (although it was emphasised that $f_{m i}$ can vary between individuals due to inter-subject variability).

$F_{m}$ is the maximum Fourier series walking force magnitude, calculated via equation (3).

$$
F_{m}=W\left(1+\sum_{n=1}^{N} \alpha_{n}\right)
$$

$C_{1}$ and $C_{2}$ are two numerical coefficients included for modelling purposes, with no physical meaning, as shown in equations (4) and (5).

$$
\begin{aligned}
C_{1} & =W\left(\frac{1}{f_{m i}}-1\right) \\
C_{2} & = \begin{cases}W\left(1-\alpha_{2}\right) & \text { if } N=3 \\
W\left(1-\alpha_{2}+\alpha_{4}\right) & \text { if } N=4\end{cases}
\end{aligned}
$$

Varela (2004) concluded that a close correlation between results from experimental and estimated vibration response to walking-induced loads, in low- 
frequency floors, is achieved when including the heel impact forces, and four harmonics, in the walking force model. Moreover, he showed that neglecting heel impacts can lead to overestimation of floor vibration responses, since such impacts counteract forces induced by the fourth harmonic, which is an interesting and rare observation. However, because the parameters associated with heel impact forces, such as $f_{m i}$ and $F_{m}$, need to be calibrated for each walking occupant, the author states that the modified version (with heel impacts), although seemingly more accurate, may be difficult to use. A regenerated force-time history of this walking force model is shown in Figure 2.

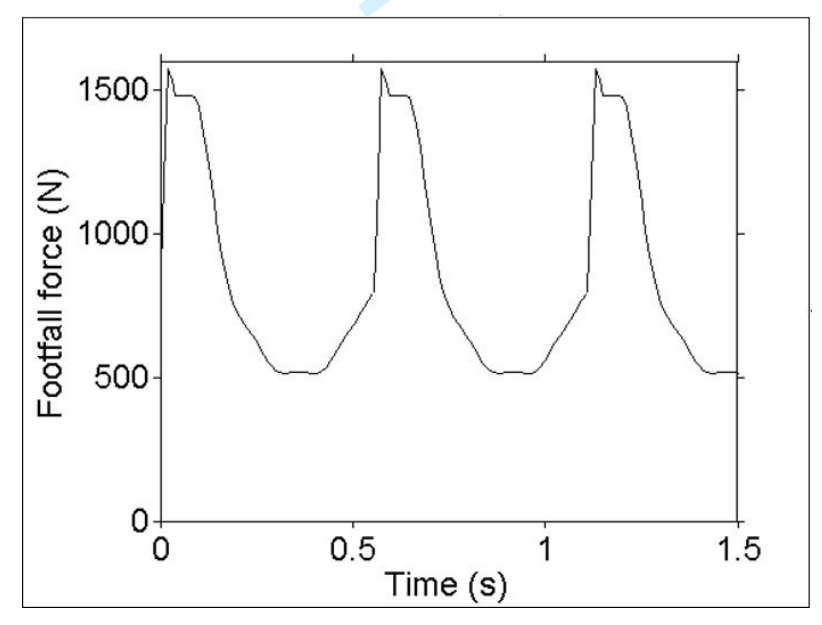

Figure 2. Adaptation of the Fourier Series WFM made by Varela (2004) to represent heel impact forces (walking frequency of $1.8 \mathrm{~Hz}$; four harmonics; person's weight of $800 \mathrm{~N}$; DLFs: $\alpha_{1}=0.5, \alpha_{2}=0.2, \alpha_{3}=$ $0.1, \alpha_{4}=0.05 ;$ and phase angles: $\left.\varphi_{1}=0, \varphi_{2}=\pi / 2, \varphi_{3}=\pi, \varphi_{4}=3 \pi / 2\right)$. 
Later, in 2007, the guideline for design of steel frame floors named HiVoSS (RFCS, 2007) proposed a polynomial function to simulate forces generated by individual footfalls, as shown in equation (6).

$$
F(t)=W\left(K_{1} t+K_{2} t^{2}+K_{3} t^{3}+K_{4} t^{4}+K_{5} t^{5}+K_{6} t^{6}+K_{7} t^{7}+K_{8} t^{8}\right)
$$

where $W$ is the person's weight; $t$ is a time instant; and $K_{i}$ is the coefficient of the term $i$ and its magnitude depends on the walking frequency.

Using the HiVoSS walking force model, a force time history of successive footfalls can be generated, by considering the single stance phase (i.e. foot-floor contact phase, comprising the heel impact, foot flat on the floor, and "toe off') and the swing phase (i.e. non-contact phase, when the leg moves to the next footfall) of each step. Between the end of the single stance phase of the one foot and the heel impact of the other, both feet are in contact with the floor, which is known as the "double stance phase". The force time history of successive footfalls is shown in Figure 3. 


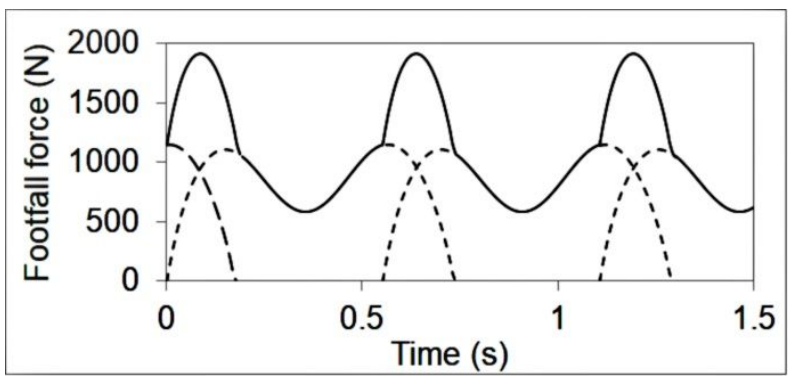

Figure 3. Time histories of force magnitudes from successive footsteps (individually shown) at walking frequency of $1.8 \mathrm{~Hz}$ and person's weight of $800 \mathrm{~N}$, according to HiVoSS (RFCS, 2007). The force signal of the sum of the footfall forces during the double stance is also shown.

In summary, the reviewed WFMs are all based on very much deterministic periodic functions, where it is assumed that the same walking forces are applied over successive gait cycles. However, as previously mentioned, there are variations of walking parameters during gait cycles of the same individual (i.e. intra-subject variability) and between different individuals (inter-subject variability). Therefore, deterministic WFMs cannot represent such a stochastic nature of a real walking scenario, where footfalls from two people, or even two footfalls by the same person, are not the same. As shown by Muhammad and Reynolds (2019), the force time history generated by the HiVoSS WFM features force magnitudes seemingly far higher than those from histories of Fourier series WFMs using parameters recommended by SCI P354, CCIP-016, CSTR 43 - AppG and AISC DG 11. In this sense, the HiVoSS WFM does not seem to be realistic. 


\subsection{Realistic approaches to office floor walking load scenarios}

The following key features are increasingly important for improving realism of vibration serviceability simulation of lightweight open-plan floors but are not represented in the current WFMs: (a) probabilistic nature of human walking; (b) multiperson walking excitation; and (c) human-structure interaction.

\subsubsection{Probabilistic walking force models. Human gait can be described by using} inherently random walking parameters that vary not only between but also for the same individual, as reported in biodynamics studies (Giakas and Baltzopoulos, 1997; Masani et al., 2002). In this respect, some WFMs comprise probability distributions of such parameters and those models are discussed as follows.

Živanović et al. (2007) developed an extension of the approach presented by Brownjohn et al. (2004), whose work proposed a WFM considering probability distributions of walking frequencies, step lengths and amplitudes of walking forces of several test subjects (inter-subject variability). The novelty presented was the inclusion of the energy content of the walking force subharmonics located between the first five most dominant harmonics of the walking forcing function. 
According to this WFM, the force is described in the time domain by including probability distributions in the Fourier series WFM, for the harmonics (equation 7) and subharmonics (equation 8) and both are summed up (equation 9).

$$
\begin{aligned}
& F_{n}(t)=W \alpha_{n}\left\{\sum_{\bar{f}_{j}=n-0.25}^{n+0.25} \bar{\alpha}_{n}\left(\bar{f}_{j}\right) \cos \left[2 \pi \bar{f}_{j} f_{s} t+\Theta\left(\bar{f}_{j}\right)\right]\right\} \\
& F_{n}^{s}(t)=W \alpha_{n}^{s}\left\{\sum_{\bar{f}_{j}^{s}=n-0.75}^{n-0.25} \bar{\alpha}_{n}^{s}\left(\bar{f}_{j}^{s}\right) \cos \left[2 \pi \bar{f}_{j}^{s} f_{s} t+\Theta\left(\bar{f}_{j}^{s}\right)\right]\right\} \\
& F(t)=\sum_{n=1}^{5} F_{n}(t)+F_{n}^{s}(t)
\end{aligned}
$$

where $n$ is the (sub)harmonic considered; $W$ is the person's weight; $\alpha_{n}$ is the DLF of the (sub)harmonic; $f_{s}$ is the step frequency; $f_{s}$ is the ratio between the frequency (range) of the harmonic analysed and the step frequency; and $\Theta\left(f_{j}\right)$ is the phase assigned to such frequency (range). It is important to note that $\bar{\alpha}_{n}$ and $f_{j}$ are parameters determined by probability distributions from a group of 500 test subjects. The superscript " $s$ " is assigned to equation (8), meaning "subharmonic".

Such a WFM, was used by Živanović and Pavić (2009) to check vibration serviceability from estimated responses of four different but nominally identical office floors. Floor responses to vibrations were obtained through response factors (explained 
later) covering simulations of 500 walkers crossing a floor (one at a time; step frequencies varied between 1.4 and $2.2 \mathrm{~Hz}$ ). In addition, response measurements from two test subjects walking across the same floor, at step frequencies of the same range, were performed. They concluded that simulations accounting for the variability of gait parameters are more comprehensive, since response predictions are not restricted to tests with a few subjects, and it leads to more realistic assessment, from a statistical point of view.

Racic and Brownjohn (2011), in turn, proposed a comprehensive WFM, including the variability of an individual walking. It covered variations of time intervals between footsteps, impulses, and shapes of footfall forces. This force model also included a more realistic distribution of the walking excitation energy over a wider frequency range. As a result, the model permitted reliable prediction of vibration responses of a structure that experienced high-amplitude responses in both high and low frequency ranges. The authors also stated that, in general, such a model could be deployed in scenarios featuring multiple occupants, but no example was provided. 


\subsubsection{Simultaneous multi-person walking load scenarios. SMPW, in the scope of this} review, refers to a small number of individuals walking at different locations on the floor surface, at the same time, which is different from a walking crowd (more usual in footbridges, shopping malls, airport and stadia concourses, concert halls, etc.).

Modern open-plan office floors normally accommodate multiple occupants, so there is a high probability of simultaneous walking of more than one occupant, at any time, in several areas. In fact, studies have reported the rise of meeting spaces in office floors (Bedford et al., 2013; Harris, 2015), which might be areas where SMPW often occurs.

According to ISO 10137 (2007), dynamic loads (including walking loads) of groups of occupants on structures are represented by the inclusion of coordination factors $C_{n}(m)$. These factors vary in the range $0<C_{n}(m)<1$, depending on the first three harmonics $(n)$ of the dynamic load and the number of individuals $(m)$. The factors are multiplied by the DLFs of these harmonics to consider the coordination level between individuals of the group.

However, the recommended coordination factors for groups featuring $m \leq 5$, is equal to 1 for all harmonics. Values of $C_{n}(m)$ are given for groups with several individuals (i.e. $m \geq 50$ ), but no information is given for groups featuring $6 \leq m \leq 49$. It should be noted that the likelihood of several people walking in groups on floors is not specified in the few investigations featuring SMPW. 
In addition, SMPW in floors includes the case of individuals walking alone or along in different paths. No consideration of the coordinated action of such small dispersed groups walking at the same time at various locations in an open plan office floor (i.e. SMPW) is provided. Indeed, coordination factors would not be applicable to the whole set of individuals simultaneously walking, since some or even all the individuals could be walking in a fully uncoordinated fashion on separate paths. Finally, the standard also lacks a detailed explanation on the classification of high, medium, and low levels of coordination in a group of individuals.

Floor vibration serviceability design guidelines that consider SMPW currently do not exist. On the other hand, there is a very small number of studies published to date that attempted to represent SMPW load scenarios in office floors, despite the fact that they are omnipresent in open plan office floors accommodating dozens of work stations and people. These few studies deserve to be discussed in detail.

Hudson and Reynolds (2014) used the probabilistic WFM of Živanović et al. (2007) to simulate in-service office load scenarios, featuring SMPW. Measurements of walking start times for occupants were carried out in an office floor in use over the most active $12 \mathrm{~h}$ period of the day for two non-successive days. A calibrated finite element (FE) model of the floor was developed and simulations of the floor's vibration response were obtained from this FE model, when the WFM was employed as an excitation source. These simulations were performed for the $12 \mathrm{~h}$ period, divided into blocks of 
two hours of data for ease of calculation and data management. The interval between walking start times of individuals was assumed to be constant throughout duration of simulations. Walking path lengths and speeds varied, so the number of walking occupants also varied at different time intervals. Experimental and simulated vibration responses were compared for the $12 \mathrm{~h}$ period. A close correlation between measured and simulated vibration responses was found, indicating the high potential of this model to predict structural responses under in-service SMPW loading. Some differences were found due to other sources of vibrations (e.g. traffic, machinery) not considered in the simulations, but having no significant impact on overall responses. Although this was the first explicit implementation of SMPW in the vibration serviceability assessment of office floors known to the authors of this review, no comparison between SPW and SMPW load scenario responses was performed in that paper.

Živanović et al. (2012) compared vibration responses measured in an office floor, due to the SPW scenario recommended by the guidelines, and the in-service walking scenario on the same floor. In SPW, four test subjects (a different test subject in each test) walked along the two most excitable walking paths (identified through modal testing), at step frequencies of $1.88 \mathrm{~Hz}$ and $2.15 \mathrm{~Hz}$ (walking path 1), and $1.98 \mathrm{~Hz}$ (walking path 2), with the help of a metronome. The subject deliberately tried to excite the floor in resonance, at one of the first three harmonics of the walking frequency. For repeatability purposes, each test was performed two times. 
Results showed that occupants were exposed to lower vibrations during inservice SMPW measured scenarios compared to those obtained in simulated SPW scenarios for all walking paths considered and for the most responsive location on the floor. Although demonstrating that SPW could be on the "safe side" in this investigation, this comparison also suggests that such simulated SPW scenarios, proposed by design guidelines, might be over-conservative, requiring unnecessary and wasteful structural modifications.

On the other hand, Chen et al. (2018) predicted walking-induced vibration levels using an FE model of a floor consisting of four composite steel-concrete floor panels. SPW and SMPW load scenarios were compared. In all scenarios, the Fourier series WFM was deployed, according to the procedure of AISC (Murray et al., 2016). The fundamental natural frequency of the floor was $4.87 \mathrm{~Hz}$. The SPW response calculation was performed by applying the WFM at a predefined position (i.e. centre of the floor panel, without moving over the structure), at a walking frequency of $1.6 \mathrm{~Hz}$. The third harmonic could then excite the first vibration mode in near resonance. For SMPW scenarios, one single-person WFM acted at the centre of the panel and the second single person WFM acted simultaneously, close to each other. Two conditions were considered, as follows. 
1. Both WFMs at the same walking frequency, but with time differences between each other.

2. Both WFMs at four sets of frequencies: $1.6 \mathrm{~Hz} / 1.6 \mathrm{~Hz} ; 1.6 \mathrm{~Hz} / 1.8 \mathrm{~Hz} ; 1.6$ $\mathrm{Hz} / 2 \mathrm{~Hz}$; and $1.6 \mathrm{~Hz} / 2.4 \mathrm{~Hz}$.

The results showed that SMPW scenarios for two people typically resulted in higher peak acceleration levels than those obtained in SPW scenarios: percentage increases ranged from $19 \%$ up to $99 \%$ across all scenarios, which highlights the potential need to consider SMPW in vibration assessment of floors, when there is a high probability of occurrence of SMPW. However, it is worth mentioning that this work focused on most unfavourable (resonance) situations and is not useful to evaluate the probability of the incidence of responses of an SMPW higher than SPW.

In conclusion, a few attempts to apply SMPW in office load scenarios so far yielded conflicting results reported in the literature. SMPW in office floor footfall dynamic load scenarios is difficult to be considered because walking patterns are more complex (e.g. individuals are usually distributed over the whole floor area, multiple potential walking paths, different occupancy rates over working hours). 
2.2.3. Human-structure interaction. HSI can be understood as the combination of active forces (from walking) and interactive forces. From the surveyed literature, it is known that HSI is capable of attenuating walking-induced vibrations on floors (Ellis and Ji, 1997; Yao, et al., 2002; Sachse, 2002; Živanović, 2015; Mohammed and Pavic, 2017b). However, effects of such an interaction, such as the changes in structural modal properties on floors, are not as well understood as they are in, say - footbridges.

To predict HSI effects in structures, approaches to dynamic modelling of humans have been used. The best known and most widely used are the mass-damperspring (MCK) models i.e. biomechanics models featuring mass, spring and damping forces in single degree of freedom (SDOF) systems representing human body. Alternatively, actuator-mass-damper-spring (AMCK) models propose to use an internal force (called interactive force) acting against the motion of the person's mass and the structure (Živanović, 2015). Both models can be employed to model active (i.e. walking) and passive (i.e. sitting or standing) occupants. However, the identification of the parameters of such models is a difficult task due to their varying nature between humans, which is also linked to changes in posture and muscle actions, especially for walking individuals.

In addition to the inherent challenges pertinent to the development of the models to the human body, HSI is difficult to represent in office floors for the following reasons: 
1. The magnitude of interactive forces depends on mode shape amplitudes along the walking paths performed by active occupants. Floor mode shapes, in their turn, are far more complex compared to beam-like structures such as footbridges. In beam-like structures, the single structural line leads 1dimensional, line, mode shapes, whereas in floors the plane of the structure leads to respective 2-dimensional, surface, mode shapes. Many likely walking path trajectories can thus exist across such mode shapes that may or may not include the most excitable points on the floor. The key problem are the closely spaced modes in floors as opposed to footbridges.

2. Walking load scenarios feature not only active occupants but also passive occupants, where both dynamically interact with the structure. It should be noted that footbridges are designed for the conveyance of pedestrians and thus passive occupants are, strictly speaking, not relevant. In floors, it is the opposite, and both active and passive should be considered.

Effects of HSI with multiple occupants on floors have been quantified in the literature. In the lightweight steel concrete composite floors investigated by Zhang et al. (2017) vibration tests were conducted in three prototypes. The tests involved varying numbers of standing occupants. Three scenarios were investigated: (a) an unoccupied floor; (b) one standing occupant; and (c) two standing occupants. 
Results showed that in most of the floors, the fundamental natural frequency increased with the presence of people. For instance, one floor presented $12.91 \mathrm{~Hz}$ (no occupants), $13.12 \mathrm{~Hz}$ (one occupant) and $13.47 \mathrm{~Hz}$ (two occupants). Also, damping ratios showed a significant increase. For example, one floor developed $1.34 \%$ of critical damping (no occupants), 5.51\% of critical damping (one occupant) and $8.50 \%$ of critical damping (two occupants). These results are in line with previous research on beam-like structures performed by Ellis and Ji (1997) and Sachse (2002). However, it should be mentioned that the tested floors were lightweight and thus more susceptible to HSI effects.

Shahabpoor et al. (2017b) also carried out tests adopting an SMPW scenario on a slender prototype beam-like slab $2 \mathrm{~m}$ wide and $11 \mathrm{~m}$ long. The modal mass of the fundamental mode of vibration was $7,128 \mathrm{~kg}$, which was about one hundred times the mass of a single occupant. Varying numbers of walking occupants (from 2 to 15) moved over the slab. Results showed rising natural frequencies and damping ratios of the slab structure as the number of occupants increased. This phenomenon was also confirmed by Mohammed and Pavic (2017a), for two, four and six occupants walking randomly over a prototype $7 \mathrm{x} 7 \mathrm{~m}$ two-way full-scale prototype floor structure.

Also, advances were made in procedures to apply HSI to load scenarios in structures. One of the most recent was developed by Shahabpoor et al. (2017a), named “interaction-based vibration serviceability assessment", which proposed to simulate 
realistically load scenarios for walking patterns featuring not only HSI but also SMPW, albeit demonstrated on a footbridge only, the moving nature of the walking forces and the stochastic nature of human gait. Where office floors are of concern, this methodology can be interpreted and adapted into the following steps.

First step: estimation of the modal properties, mass, frequency, and damping of the occupied structure $\left(m_{o s}, f_{o s}, \zeta_{o s}\right)$, by simulating various SMPW load scenarios. Modal properties of the SDOF occupant body models are scaled by $\Phi_{\mathrm{n}}\left(x_{p}\right)$, as shown in equations (10) and (11).

$$
\begin{aligned}
& C_{p}=\Phi_{n}\left(x_{p}\right) c_{p} \\
& K_{p}=\Phi_{n}\left(x_{p}\right) k_{p}
\end{aligned}
$$

where $C_{p}$ and $K_{p}$ are, respectively, the scaled damping and stiffness coefficients of the SDOF occupant body model ( $c_{p}$ and $k_{p}$ are the respective non-scaled coefficients), where such scaling represents the level of interaction that depends on the location occupied by the floor user; and $\Phi_{\mathrm{n}}\left(x_{p}\right)$ is the amplitude of the mode $n$ at a given location $x_{p}\left(\right.$ and $\left.x_{p}=v_{p} t\right)$, depending on occupant walking speed $v_{p}$ (assumed constant) at time instant $t$. The most excitable spots have $\Phi_{\mathrm{n}}\left(x_{p}\right)$ close to 1 , which is a high interaction level, for unit-normalised modal amplitudes. The mode shape amplitudes are those of 
the empty floor because they are assumed to be unchanged between empty and occupied scenarios. Several scenarios are simulated for different sets of walking parameters and paths of active occupants. The process is repeated until values of $m_{O S} f_{o S} \zeta_{o s}$ converge. Second step: to account for the level of HSI, the physical walking force of each walker, $f_{p}(t)$, is scaled by the mode shape amplitudes $\Phi_{\mathrm{n}}\left(x_{p}\right)$ at the location where the force is acting at time $t$ (equation 12).

$$
F_{p, n}(t)=\Phi_{n}\left(x_{p}\right) f_{p}(t)
$$

where $F_{p, n}(t)$ is the modal walking force of the occupant $p$ corresponding to mode $n$. Figure 4 shows physical walking forces from two occupants, $f_{1}(t)$ and $f_{2}(t)$, scaled by mode shape amplitudes, $\Phi_{2}\left(v_{1} t\right)$ and $\Phi_{2}\left(v_{2} t\right)$ of the second mode, resulting in modal walking forces $F_{1,2}(t)$ and $F_{2,2}(t)$. 


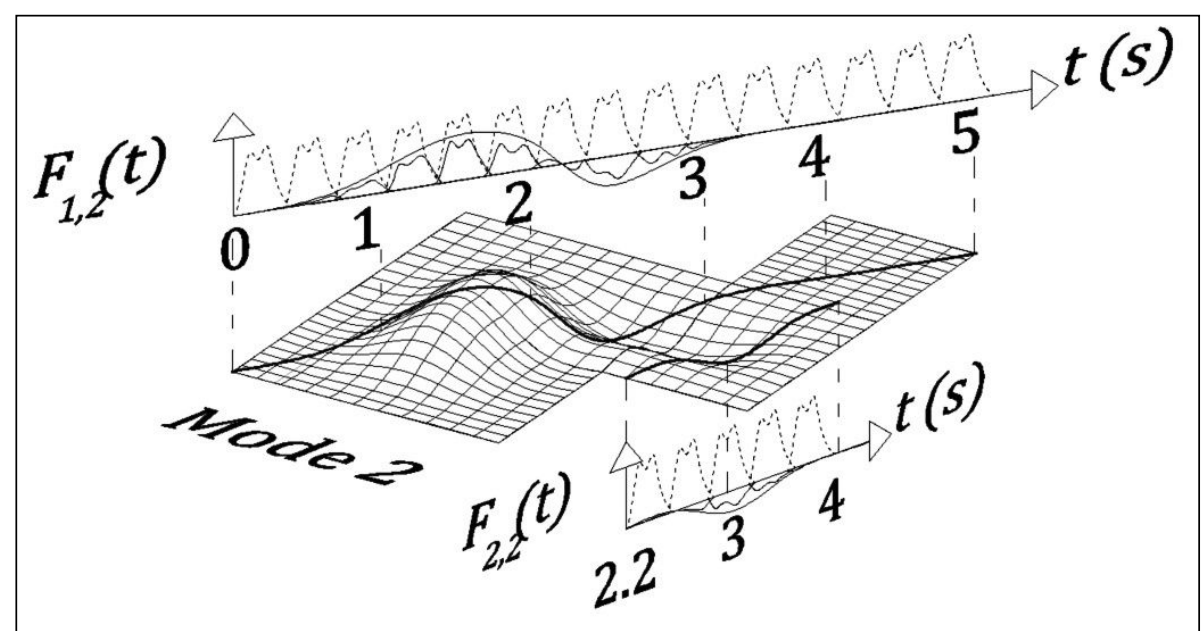

Figure 4. Modal walking forces of two occupants in an office, according to Shahabpoor et al. (2017a).

The sum of individual modal walking forces, $F_{p, n}(t)$, according to the start and end time of the walking of each occupant (where $N_{p}$ is the number of occupants in the load scenario), yields the total modal walking force $F_{n}(t)$, exciting mode $n$, as shown in equation (13) and Figure 5.

$$
F_{n}(t)=\sum_{p=1}^{N_{p}} F_{p, n}(t)
$$




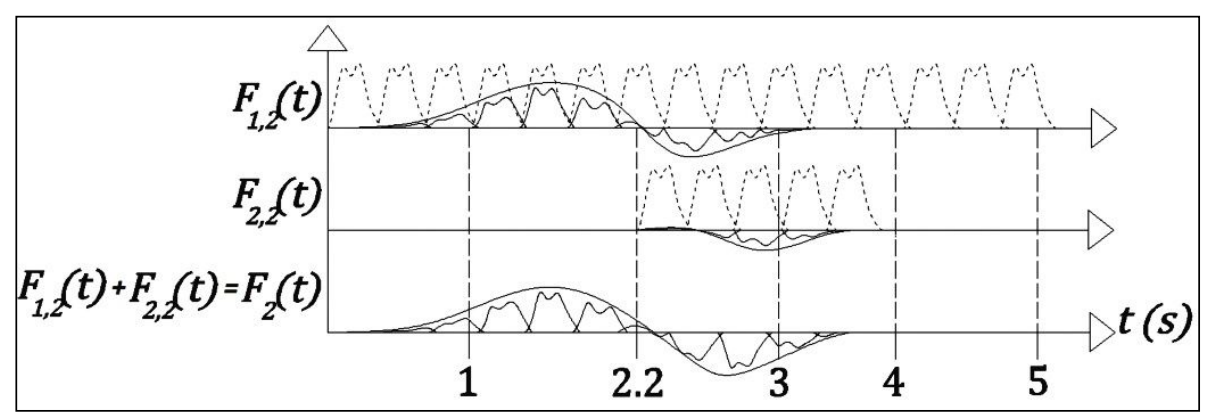

Figure 5. Modal walking forces of occupant $1, \mathrm{~F}_{1,2}(\mathrm{t})$ and occupant $2, \mathrm{~F}_{2,2}(\mathrm{t})$, summed up to yield the total modal walking force exciting mode $2, \mathrm{~F}_{2}(\mathrm{t})$, based on Shahabpoor et al. (2017a).

Third step: the generalised response $Q_{n}(t)$ is calculated by applying $F_{n}(t)$ on the SDOF system corresponding to mode $n$. By scaling $Q_{n}(t)$ by mode shape amplitudes, $\Phi_{n}\left(x_{p}\right)$, the physical response of this mode felt by the occupant $p$ is obtained, at the occupant's location on the floor $\left(x_{p, n}\right)$, as shown in equation (14) and Figure 6.

$$
x_{p, n}(t)=\Phi_{n}\left(x_{p}\right) Q_{n}(t)
$$

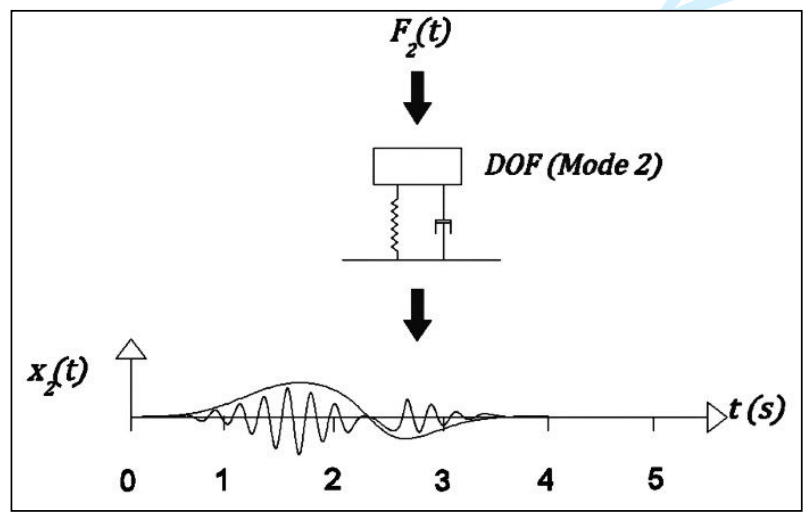


Figure 6. Modal floor response scaled by the mode shape amplitudes to yield the physical floor responses felt by an occupant, based on Shahabpoor et al. (2017a).

The process is repeated for all $N_{m}$ excited modes, so their sum yields the total response experienced by occupant $p$, or $x_{p}$, as shown in equation (15).

$$
x_{p}(t)=\sum_{1}^{N_{m}} x_{p, n}(t)
$$

It should be noted that equation (15) calculates the floor vibration response for the active occupant during walking. This is because the work of Shahabpoor et al. (2017a) was essentially conceived for footbridges. More equations would be needed to calculate the response at the location of the sitting occupants as well. Additionally, prolonged vibration exposure of floor occupants who may be sitting or moving during a working day should also be considered. 


\subsubsection{Body movement tracking in office floors. Tracking systems can be utilised to} monitor movement of people around an office during a time period, identifying walking patterns (e.g. areas with more walkers in a given time interval, locations featuring passive occupants, and most used walking paths).

Body movement tracking systems employ different techniques. Some of them are: (a) visual-based tracking (Teixeira et al., 2010); (b) Ultra-Wide Band (UWB) (Mohammed and Pavic, 2017c) and (c) Radio-Frequency Identification (RFID) (Adame et al., 2018).

Apart from the benefits, the following challenges in using these techniques are useful to note:

1. Privacy concerns.

2. Distinction between physically similar people for visual-based tracking (Teixeira et al., 2010);

3. Massive data management (Stojanović and Stojanović, 2014);

4. Distinction between people walking/standing/sitting closely together, for visual-based tracking;

5. Wellbeing of occupants due to the usage of wearable tracking devices, for UWB-based tracking;

6. Occlusions, for visual-based tracking; 
7. High-cost acquisition and implementation.

It is worth mentioning the work of Mohammed and Pavic (2017c), which demonstrates the use of movement tracking systems pertinent to the VSA of office floors. Its results showed that it is possible to measure, simultaneously, the position of occupants wearing UWB tags, walking forces using wearable inertial measurement unit (IMUs), and corresponding floor responses using accelerometers, with acceptable accuracy. That paper demonstrated potential usage of such techniques for improving VSA methods for office floors and identifies upcoming research directions in this field.

2.2.5. Floor occupancy rate. The vibration serviceability of office floors due to walking loads is also linked to their occupancy, since the number of occupants is an essential factor in simulations of load scenarios. Therefore, investigations of occupancy rates in office floors deserve attention.

Bedford et al. (2013) commented that the number of workstations in an office is not an accurate measure of its occupancy, as flexible workstyles (e.g. shared workstations and mobile work) are increasingly common today. In addition, floor occupancy rates change during the day. Yang et al. (2011) and Labeodan et al. (2013) presented an example of a typical daily pattern of floor occupancy during working hours (Figure 7). 


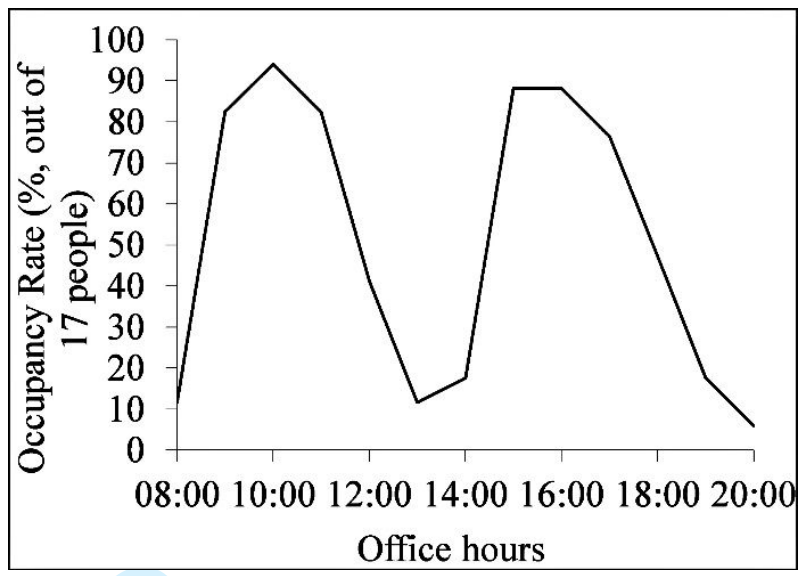

Figure 7. Rate of occupancy during working hours based on Yang et al. (2011).

The steep increase and decrease in occupancy i.e. pedestrian flow around the beginning, middle (lunch break), and end of the working day could be associated with SMPW scenarios. Such SMPW scenarios would correspond to occupants moving intensively over the floor while entering or leaving the office, but currently there is no study to quantify this effect for the purpose of SMPW.

Živanović (2015) points out further features of realistic walking scenarios missing in the literature. These are human-human interaction (the gait cycle of a person is influenced by others in simultaneous walking) and human reaction to perceived vibrations (the extent to which perceived vibrations influence human activities, including walking). Although worthy of note, these features are beyond the scope of this review, as they are unlikely to be relevant for an office design scenario, where 
amplitudes of floor vibration are relatively small compared to what is happening in footbridges, the main subject of Živanović's (2015) paper.

As previously pointed out, potential complexity in the walking paths and the possibility of several occupants being simultaneously involved in multi-person walking at different floor locations requires further research. Data relating to the locations, posture and activity of human occupants in office floors are essential as inputs in simulations of office floor response to vibrations. Currently, in the context of VSA, these data are practically non-existent in the published literature and do not appear in any contemporary office floor design guidelines.

\subsection{Office floor layouts}

The organisation of an office space depends on its spatial planning. It must provide a proper circulation of occupants, by accounting for some characteristics, such as the locations where people expected to walk most and the likely number of people walking simultaneously. Therefore, space planning defines conditions of walking load scenarios, which, in turn, drive (together with the modal properties of the structure) floor responses.

The work of Harris (2015) showed that contemporary workstyles are more interactive and collaborative than in the past, now permitting individuals to perform 
tasks mutually and dynamically within work teams. Evidence of such a change was presented previously by Bedford et al. (2013), who analysed a sample of 1,331 office floors from 381 properties in the United Kingdom. According to this survey, the space planning of offices presented following overview of utilisation of the floor area:

1. In 1995: $80 \%$ fixed desks, $15 \%$ meeting spaces, and 5\% support spaces.

2. In 2013: 55\% shared desks, 5\% drop-in desks, $35 \%$ meeting spaces, and 5\% support spaces.

Prichard (2011) also states that contemporary space planning seeks to establish larger workspaces, without 'obstacles' (i.e. open-plan offices) so that it brings ease of access to multiple floor panels, facilitating circulation of occupants and collaborative work. This is the opposite of cellular office floors, more common in the past, where workers used to perform their tasks individually.

Therefore, space planning affects the way occupants move around offices, leading to potential walking load scenarios featuring: (a) paths along which walking loads will often excite the floor which is important for increasing realism of vibration serviceability considerations; (b) working hours at which certain floor areas may be most excited; and (c) areas where active and passive occupants are close to each other. However, changes in the original office layout can modify 'established' dynamic 
loading scenarios, which may lead to unacceptable structural responses, as shown in case studies investigated by Hanagan (2005).

In office floors, the receivers of vibrations are the sitting or standing occupants who are stationary in both cases. Thus, it is crucial to identify the locations that such passive individuals occupy when walking loads excite the floor. Also, locations of walking occupants, are equally important. Locations of occupants are linked to office layout types and, from the surveyed literature, three main types of office floors can be considered.

Type 1: In this layout (Figure 8), walking areas are located around the edges of the floor panel (or floor bay). Then, it is likely that walking loads are applied near structural supports around the edges (walls, columns and beams), so floor vibrations are attenuated.

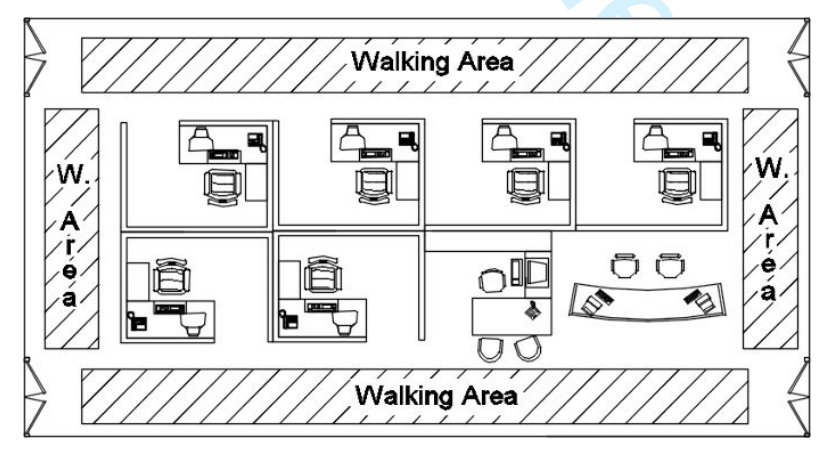

Figure 8. Office floor layout type 1. 
Type 2: This layout is frequently found in open-plan offices. Usually, a large walking area is located at the centre of the floor (Figure 9). Although the vibration sources are acting at locations with no stiffening elements nearby (i.e. column-free floors), passive occupants, or at least some of them, have the benefit of being located near structural elements, and vibrations are reduced in such locations.

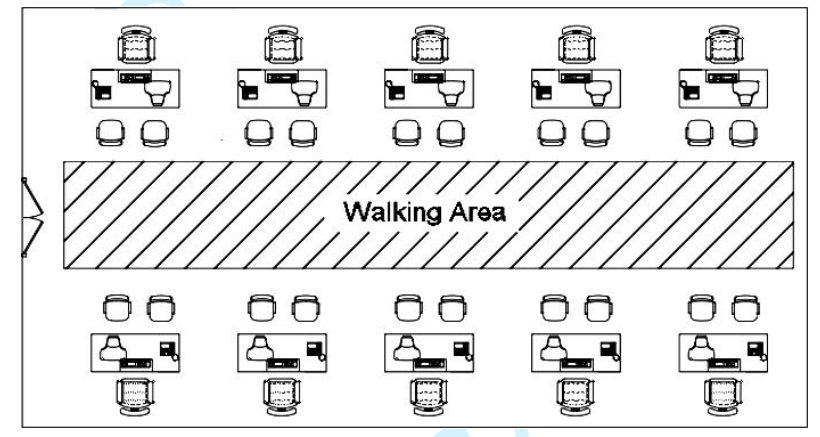

Figure 9. Office floor layout type 2.

Type 3: The walking area assumes a grid-like pattern (Figure 10). Due to the location of workstations and walking paths, both active and passive occupants are evenly distributed over the floor. Therefore, the occupants are more likely to occupy the same critical areas, potentially resulting in objectionable vibrations. 


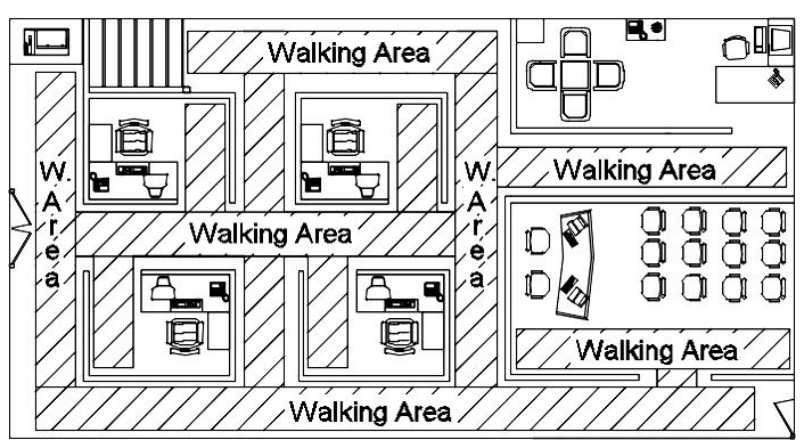

Figure 10. Office floor layout type 3.

Architectural coordination between the locations of the working areas and key structural elements should be performed at the design stage. This is to allocate the footfall dynamic loads as close as possible to the key structural supports, such as primary beams and columns, which is a well-known strategy for reducing floor vibration levels (Murray et al., 2016).

The architectural layout also influences the maximum pacing frequency, which can be limited by the existence of non-structural elements in the form of walking path 'obstacles', or by shorter walking paths in a given floor area (Smith et al., 2009; Van Engelen and Graham, 2018). Such a limitation also occurs to the step length (Varela, 2004).

Additionally, non-structural elements in an office layout (e.g. furniture and fullheight partitions) can enable a more favourable distribution of footfall-induced dynamic loads by serving as obstacles to avoid critical SMPW load scenarios. Venuti and Reggio 
(2018) conducted a similar study using pedestrian barriers in footbridges to control pedestrian streams, changing their trajectory and reducing their walking speed, and such a procedure showed satisfactory outcomes to reduce walking-induced structural vibrations. This strategy deserves further investigation for offices and could be potentially recommended by design guidelines.

In summary, to achieve realistic load scenarios, one should consider: (a) contemporary office space planning for collaborative work (more chances of SMPW) and (b) office layout types can lead to (un)favourable distributions of walking forces over the floor surface, affecting the walking frequency, speed and step length. 


\section{Vibration Transmission Path: the office floor}

Modal properties of the vibration transmission path depend on the proportion of active and passive walkers and can vary. Such variations in modal properties can also occur due to non-structural elements (e.g. full-height partitions, false floors, suspended ceilings, services, furniture, façade) potentially affecting floor vibration responses. This is especially so for full-height partitions, which are the most widely used non-structural elements on building floors (Devin and Fanning, 2019).

The additional damping due to the presence of non-structural elements in floors has been discussed in the literature (Pernica, 1987; Cantieni and Biro, 2005; Hanagan, 2005). However, structural damping is typically caused by the relative motion between adjacent (structural or non-structural) elements, which makes it difficult to estimate accurately (Devin and Fanning, 2019). Structural stiffness, in its turn, is related to construction materials and structural configuration (Kareem and Gurley, 1996; Liang and Lee, 1991).

There are several studies that have attempted to quantify the stiffening effect of non-structural elements. Using FE modelling, Dulińska and Fabijańska (2012) identified an average increase of $12.6 \%$ on vertical natural frequencies in reinforced concrete building floors due to non-structural brick walls. Miskovic et al. (2009) showed an average difference of $6 \%$ in the natural frequencies of two nominally identical 
composite steel concrete floors due to different layouts of non-structural full-height partitions and differences in floor mode shapes were also found.

Given the potential of non-structural elements to change floor dynamic properties and attenuate vibrations considerably, it is emphasised that further investigations are required (Muhammad and Reynolds, 2019; Devin and Fanning, 2019) in order to improve modelling of these in design guidelines, so that not only damping and mass, but also stiffness of non-structural elements is taken into account properly. 


\section{Vibration Receivers: the office occupants}

Pavic et al. (2001) remarked that different metrics have been established by contemporary guidelines to assess floor vibration serviceability. The most known are peak accelerations, root mean square accelerations (RMS) and vibration dose values (VDVs). Peak accelerations do not represent well the dynamic behaviour of a floor since this single acceleration value cannot evaluate well the acceptability of the floor vibration responses to walking activities occurring over a prolonged time interval. One or 100 floor acceleration peaks due to walking, even when they have the same amplitude, are perceived as completely different by humans. Therefore, the focus of this section is on long term measures such as RMS accelerations and their statistics and VDVs. The last subsection presents probabilistic approaches to floor vibration assessment as a recent alternative to check vibration serviceability of office floors.

It is important to mention that a vibration weighting should be applied to acceleration time histories because human sensitivity to vibrations depend on their direction, frequency and type of activity. For vibration frequencies between $4-10 \mathrm{~Hz}$ (most common in low-frequency floors), such a weight is equal to 1 (ISO 2631-1, 1997). 


\subsection{Root mean square (RMS) acceleration}

Assessment through RMS acceleration was first introduced by the international standard ISO 2631-1 (1997). The calculation of RMS accelerations is shown in equation (16).

$$
R M S=\sqrt{\frac{\int_{t_{1}}^{t_{2}} a(t)^{2} d t}{t_{2}-t_{1}}}
$$

where $a(t)$ is the frequency-weighted acceleration value at a time instant $t, t_{1}$ and $t_{2}$ correspond to the start and end of the integration time.

Previously, an integration time of $10 \mathrm{~s}$ was usually recommended (ISO 10137, 2007). The guideline CCIP-016 (Willford and Young, 2006) recommends the integration time of $1 / f_{s}$, which seems more realistic, since the time to make a single step of walking is considered. However, the most common integration time nowadays used is $1 \mathrm{~s}$. The highest $1 \mathrm{~s}-\mathrm{RMS}$ acceleration from the acceleration time history is the maximum transient vibration value (MTVV). When the MTVV is divided by the baseline RMS acceleration of $0.005 \mathrm{~m} / \mathrm{s}^{2}$ (ISO 10137, 2007), it yields the response (R) factor (equation 17). 


$$
R=\frac{M T V V}{0.005}
$$

R factors are currently adopted by the guidelines CSTR 43 - AppG, CCIP-016, SCI P354, and HiVoSS. The guidelines CCIP-016, CSTR 43 - AppG, SCI P354 and HiVoSS recommend a limit of $\mathrm{R}<8$ for busy offices and $\mathrm{R}<4$ for quiet offices, although they do not define what busy or quiet means. It is possible that this ambiguity led to such a large percentage of unsatisfactory performance of code compliant structures identified in the IStructE survey mentioned at the beginning of this review. The Health Technical Memorandum, or HTM 08-01 (United Kingdom Department of Health, 2013), which is a document that states design, installation and operation procedures for healthcare facilities, also recommends $\mathrm{R}<8$ for offices.

Assessments using MTVVs are not adequate because it is too sensitive to short duration acceleration peaks (Reynolds and Pavic, 2015), which might not cause significant disturbance to occupants.

\subsection{Vibration dose value (VDV)}

In 2008, the BS 6472-1 (BSI, 2008) introduced the VDV-based assessment, instead of the traditional RMS assessment. VDV is a cumulative value obtained through the root mean quad of either measured or calculated acceleration levels (equation 18). 


$$
V D V=\left[\int_{0}^{T} a(t)^{4} d t\right]^{1 / 4}
$$

where $a(t)$ is the frequency-weighted acceleration value at a time instant $t$, and $T$ is the total period of the day in which vibrations may occur.

BS 6472 states a range of limiting VDV values for different probabilities of adverse comments from occupants: for a low probability, the $0.4-0.8 \mathrm{~m} / \mathrm{s}^{1.75}$ range is recommended.

Such a metric has the merit of considering the time exposure to vibration. Indeed, this assessment metric could be used to cover all periods of stationarity and movement across the floor.

However, it is important to stress that the recommended VDV limits (such as the ones proposed by BS6472) need much improved calibration, since such limits are disproportionately higher than VDV values measured in monitored, and demonstrably problematic, full-scale and operational built floors (Reynolds and Pavic, 2015; Muhammad et al., 2018). 


\subsection{Probabilistic assessment of office floor vibrations}

As previously mentioned, human gait has a stochastic nature, which means that each subject applies walking-induced forces of different amplitudes. Therefore, for a given scenario, vibration levels need to be analysed statistically.

Contributions to the literature (such as Živanović and Pavić, 2009; Hudson and Reynolds, 2014; Reynolds and Pavic, 2015) have deployed cumulative distributions of $\mathrm{R}$ factors from various load scenarios, throughout working hours, to yield probabilities of exceedance. They concluded that this statistical approach might lead to a more realistic methodology, since it considers exposure times during office working hours and the variability of the walking parameters among office occupants.

Additionally, limits for the probability of exceedance need to reflect typical structural response to vibrations. The $5 \%$ probability of exceedance is used, as by Hudson and Reynolds (2014), but this is done rather arbitrarily as there is still no scientific justification for this value.

So far, no floor design guidance has proposed recommendations for such a probabilistic assessment of vibration responses, which suggests that future research may be needed if the idea of probabilistic floor vibration response and its assessment is to be utilised in practical design. Such methods exist in many other areas of engineering dealing with random vibrations, such as wind or wave loading and fatigue assessment. 


\section{Conclusions}

Case studies of excessive office floor vibrations due to footfall-induced dynamic loads have been frequently reported. These indicate the need for more realistic assessment of floor vibration serviceability by design guidelines worldwide.

Realistic assessment approaches should include better representation of walking load scenarios, which involves consideration of stochastic single- and multi-person walking force models, accounting for actual architectural office floor layouts, and adequate vibration serviceability assessment methods. In this sense, the main findings of this literature review are:

1. Walking force models should represent both intra-subject and inter-subject variabilities of office occupants, which may significantly affect structural response. This would lead to a probabilistic approach of obtaining the response of office floors to occupant-induced loads. Currently used deterministic models are increasingly obsolete and potentially wasteful in representing walking loads in modern lightweight and open plan office floors.

2. Human body movement tracking techniques can provide data to simulate existing dynamic load scenarios featuring multiple walkers and passive occupants in modern offices. This can reveal (un)favourable characteristics of 
such scenarios to the dynamic behaviour of the structure. To date, such data are incipient.

3. The high level of human-structure interaction in modern office floors (which are lightweight, long-span and open-plan) is likely to influence their structural responses significantly, although it is not considered in current response prediction methods. Both active and passive occupants should be modelled as dynamic systems, to account for their effect on the overall structural response.

4. Further investigations of dynamic effects of non-structural elements (particularly full-height partitions) on floor dynamic behaviour are needed, since those improve significantly vibration performance of modern offices, but this is yet to be considered explicitly by design guidelines.

5. Probability of exceedance or vibration-dose-based approaches might be a more realistic way of assessing office floor vibrations, since they consider not only the amplitude but also the likelihood of the occurrence as well as the duration of the vibration exposure (there is an increasing evidence that these two factors affect human perception of floor vibrations) which are crucial for human perception of vibrations. 


\section{Acknowledgements}

This study was financed in part by the Coordenação de Aperfeiçoamento de Pessoal de Nível Superior - Brasil (CAPES) - Finance Code 001 (scholarship no. 88881.128626/2016-01). 


\section{Conflicts of Interest}

The authors state that there are no conflicts of interest to declare. 


\section{References}

Adame, T., Bel, A., Carreras, A., Melià-Seguí, J., Oliver, M., \& Pous, R. (2018). CUIDATS: An RFID-WSN hybrid monitoring system for smart health care environments. Future Generation Computer Systems, 78, 602-615. https://doi.org/10.1016/j.future.2016.12.023

Bachmann, H., Ammann, W. J., Deischl, F., Eisenmann, J., Floegl, I., Hirsch, G. H., Steinbeisser, L. et al. (1995). Vibration Problems in Structures. Birkhauser, Basel, Boston, Berlin, 1995. https://doi.org/10.1007/978-3-0348-9231-5

BCSA. (2016). Steel Construction Floor Vibrations. Steel for Life. April, 2016.

Bedford, M., Harris, R., King, A, \& Hawkeswood, A (2013). Occupier Density Study. British Council for Offices. Avaliable at: http://www.bco.org.uk/Research/Publications/OccupierDensity-Study-2013.aspx

Brownjohn, J. M. ., Pavic, A., \& Omenzetter, P. (2004). A spectral density approach for modelling continuous vertical forces on pedestrian structures due to walking. Canadian Journal of Civil Engineering, 31(1), 65-77. https://doi.org/10.1139/103-072

Brownjohn, J. M. W. (2001). Energy Dissipation from Vibrating Floor Slabs due to HumanStructure Interaction. Shock and Vibration, 8(6), 315-

323. https://doi.org/10.1155/2001/454139.

BSI. (2008). BS 6472-1: Guide to evaluation of human exposure to vibration in buildings. BSI British Standards Institution.

Cantieni, R., \& Biro, T. (2005). Office Floor Vibrations: Modal Parameter Identification And Vibration Monitoring. Proc. Eurodyn 2005, 533-538. 
Cantieni, R.; Pietrzko, S. \& Deger, Y.. (1998). Modal Investigation of an Office Building Floor. In: $16^{\text {th }}$ International Modal Analysis Conference. Society for Experimental Mechanics, Santa Barbara, CA, 1172-1178.

Chen, S., Zhang, J., \& Zhang, R. (2018). Human-induced vibration of steel - concrete composite floors. In: Proceedings of the Institution of Civil Engineers - Structures and Buildings, 171(1), 50-63.

Devin, A., \& Fanning, P. J. (2019). Non-structural elements and the dynamic response of buildings: A review. Engineering Structures, 187(February), 242-250. https://doi.org/10.1016/j.engstruct.2019.02.044

Díaz, I. M., \& Reynolds, P. (2010). Acceleration feedback control of human-induced floor vibrations. Engineering Structures, 32(1), 163-173. https://doi.org/10.1016/j.engstruct.2009.09.003

Dulińska, J. M., \& Fabijańska, M. (2012). Influence of Non-Structural Elements on Dynamic Response of Multi-Storey Rc Building to Mining Shock. International Journal of Civil and Environmental Engineering, 6(3), 222-227. Retrieved from https://pdfs.semanticscholar.org/277b/ed2a5e6c8d7c50a0eb48603373cc904cf930.pdf

Ellis, B. R., \& Ji, T. (1997). Human-structure interaction in vertical vibrations. Proceedings of the Institution of Civil Engineers, Structures and Buildings, 122(1), 1-9.

Giakas, G., \& Baltzopoulos, V. (1997). Time and frequency domain analysis of ground reaction forces during walking: An investigation of variability and symmetry. Gait and Posture, 5(3), 189-197. https://doi.org/10.1016/S0966-6362(96)01083-1

Hanagan, L. M. (2005). Walking-Induced Floor Vibration Case Studies. Journal of 
Architectural Engineering, 11(1), 14-18. https://doi.org/10.1061/(ASCE)10760431(2005)11:1(14)

Hanagan, LM and Chattoraj, MC 2006, A whole building cost perspective to floor vibration serviceability. in AEI 2006: Building Integration Solutions - Proceedings of the 2006 Architectural Engineering National Conference. vol. 2006, pp. 37, AEI 2006, Omaha, NE, United States, 3/29/06. https://doi.org/10.1061/40798(190)37

Harris, R. (2015). The changing nature of the workplace and the future of office space. Journal of Property Investment and Finance, 33(5), 424-435. https://doi.org/10.1108/JPIF-052015-0029

Hudson, E. J; Reynolds, P. (2014). Implications of structural design on the effectiveness of active vibration control of floor structures. Structural Control and Health Monitoring, (21), 685-704. https://doi.org/10.1002/stc

ISO. (1997). Mechanical Vibration and Shock - Evaluation of Human Exposure to Whole-body Vibration - Part 1: General Requirements. ISO 2631-1. International Standardization Organisation, Geneva, Switzerland.

ISO (2007). Bases for Design of Structures - Serviceability of Buildings Against Vibrations. ISO 10137. International Standardization Organisation, Geneva, Switzerland.

Kareem, A., and Gurley, K. (1996). Damping In structures: Its evaluation and treatment of uncertainty. Journal of Wind Engineering and Industrial Aerodynamics, 59(2-3), 131157. https://doi.org/10.1016/0167-6105(96)00004-9

Labeodan, T., Maaijen, R., \& Zeiler, W. (2013). The human behavior : a tracking system to follow the human occupancy. Proceedings of the International Conference on Cleantech 
for Smart Cities and Buildings (CISBAT 2013), 513-518.

Liang, Z., and Lee, G. C. (1991). Damping of Structures: Part 1 - Theory of Complex Damping by. National Center for Earthquake Engineering Research. Technical Report NCEER-910004.

Lindenberg, R. E. and Fraczek, J. (2013). From Old to New: Vibration Issues with Old Buildings and Their New Office Spaces. In: Proccedings of Structures Congress 2013: Bridging Your Passion with Your Profession, 3, 1747-1758.

Masani, K., Kouzaki, M., \& Fukunaga, T. (2002). Variability of ground reaction forces during treadmill walking. Journal of Applied Physiology, 92(5), 1885-1890. https://doi.org/10.1152/japplphysiol.00969.2000

Miskovic, Z., Pavic, A., \& Reynolds, P. (2009). Effects of full-height nonstructural partitions on modal properties of two nominally identical building floors. Canadian Journal of Civil Engineering, 36(7), 1121-1132. https://doi.org/10.1139/109-055

Mohammed, A. S., \& Pavic, A. (2017a). Effect of Walking People on Dynamic Properties of Floors. Procedia Engineering, 199, 2856-2863. https://doi.org/10.1016/j.proeng.2017.09.561

Mohammed, A. S., \& Pavic, A. (2017b). Evaluation of Mass-Spring-Damper Models for Dynamic Interaction Between Walking Humans and Civil Structures. In J. Caicedo \& S. Pakzad (Eds.), Dynamics of Civil Structures, Volume 2. Conference Proceedings of the Society for Experimental Mechanics Series (pp. 169-177). Springer, Cham. https://doi.org/10.1007/978-3-319-54777-0_21

Mohammed, A. S., \& Pavic, A. (2017c). Utilising an advanced technology of people tracking in 
vibration serviceability application, $2-9$.

Muhammad, Z. O., \& Reynolds, P. (2019). Vibration Serviceability of Building Floors:

Performance Evaluation of Contemporary Design Guidelines, 33(2), 1-17.

https://doi.org/10.1061/(ASCE)CF.1943-5509.0001280

Muhammad, Z., Reynolds, P., Avci, O., \& Hussein, M. (2018). Review of Pedestrian Load Models for Vibration Serviceability Assessment of Floor Structures. Vibration, 2(1), 1-24. https://doi.org/10.3390/vibration2010001

Murray, T. M., Allen, D. E., \& Ungar, E. E. (2016). Steel Design Guide Series 11 Floor Vibrations Due to Human Activity. American Institute of Steel Construction, Inc., 1-71.

Nguyen, T., Gad, E., Wilson, J., and Haritos, N. (2014). Mitigating Footfall-Induced Vibration in Long-Span Floors, Australian Journal of Structural Engineering, 15:1, 97 109, DOI: 10.7158/13287982.2014.11465150 https://doi.org/10.7158/S12-061.2014.15.1

Pavic, A., Miskovic, Z., \& Reynolds, P. (2007). Modal Testing and Finite-Element Model Updating of a Lively Open-Plan Composite Building Floor. Journal of Structural Engineering, 133(4), 550-558. https://doi.org/10.1061/(ASCE)07339445(2007)133:4(550)

Pavic, A., Reynolds, P., Waldron, P., \& Bennett, K. J. (2001). Critical review of guidelines for checking vibration serviceability of post-tensioned concrete floors. Cement and Concrete Composites, 23(1), 21-31. https://doi.org/10.1016/S0958-9465(00)00069-X

Pavic, A., \& Willford, M. R. (2005). Vibration Serviceability of Post-tensioned Concrete Floors - CSTR43 App G. Appendix G in Post-Tensioned Concrete Floors Design Handbook Technical Report 43. Slough, UK: Concrete Society. 
Pernica, G. (1987). Effect of architectural components on the dynamic properties of a long-span floor system. Canadian Journal of Civil Engineering, 14(4), 461-467. https://doi.org/10.1139/187-070

Prichard, S. (2011). Serviceability design of building structures which are sensitive to vibration. In: Proceedings of the International Conference on Structural Dynamics (EURODYN 2011), 970-977, 4-6 July, Leuven, Belgium.

Property Industry Alliance. (2017). Property Data Report 2017.

Racic, V., \& Brownjohn, J. M. W. (2011). Stochastic model of near-periodic vertical loads due to humans walking. Advanced Engineering Informatics, 25(2), 259-275. https://doi.org/10.1016/j.aei.2010.07.004

Reynolds, P., \& Pavic, A. (2003). Effects of False Floors on Vibration Serviceability of Building Floors. II: Response to Pedestrian Excitation. Journal of Performance of Constructed Facilities, 17(2), 87-96. https://doi.org/10.1061/(ASCE)0887$3828(2003) 17: 2(87)$

Reynolds, P., \& Pavic, A. (2015). Reliability of Assessment Criteria for Building Floor Vibrations Under Human Excitation. 50th UK Conference on Human Responses to Vibration, 277-282.

RFCS (2007). Human Induced Vibrations ofSteel Structures (HiVoSS) - Vibration Design of Floors: Background Document; European Comission - Research Fund for Coal and Steel: Brussels, Belgium, 2007.

Sachse, R. (2002) The Influence of Human Occupants on the Dynamic Properties of Slender Structures. PhD Thesis, University of Sheffield, Sheffield, UK. 
Setareh, M., Ritchey, J. K., Baxter, A. J., Murray, T. M. (2006). Pendulum Tuned Mass Dampers for Floor Vibration Control. Journal of Performance of Constructed Facilities, 20(February), 64-73. https://doi.org/10.1061/(ASCE)0887-3828(2006)20:1(64)

Shahabpoor, E., Pavic, A., \& Racic, V. (2017a). Structural vibration serviceability: New design framework featuring human-structure interaction. Engineering Structures, 136, 295-311. https://doi.org/10.1016/j.engstruct.2017.01.030

Shahabpoor, E., Pavic, A., Racic, V., \& Zivanovic, S. (2017b). Effect of group walking traffic on dynamic properties of pedestrian structures. Journal of Sound and Vibration, 387, $207-$ 225. https://doi.org/10.1016/j.jsv.2016.10.017

Smith, A. L., Hicks S. J., Devine, P. J. (2009). Design of Floors for Vibration: (2nd Edition, February 2009 ). Steel Construction Institute (SCI): Berkshire, UK.

Stojanović, D., \& Stojanović, N. (2014). Indoor Localization and Tracking: Methods, Technologies and Research Challenges. Facta Universitatis, Series: Automatic Control and Robotics, 13(1), 57-72. https://doi.org/10.3390/s16050678

Teixeira, T., Dublon, G., \& Savvides, A. (2010). A Survey of Human-Sensing: Methods for Detecting Presence, Count, Location, Track, and Identity. ACM Computing Surveys, 5(1), $1-35$.

UKDH. (2013). Specialist services: Health Technical Memorandum 08-01: Acoustics, 48. United Kingdom Department of Health. Available at: https://www.gov.uk/government/uploads/system/uploads/attachment_data/file/144248/HT M_08-01.pdf

Van Engelen, N. C., \& Graham, J. (2018). Comparison of Prediction and Measurement 
Techniques for Pedestrian-Induced Vibrations of a Low-Frequency Floor. Structural Control and Health Monitoring, 1-13. https://doi.org/10.1002/stc.2294

Varela, W. D. (2004). Modelo Teórico-experimental para Análises de Vibraçoes Induzidas por Pessoas Caminhando sobre Lajes de Edifícios. Ph.D. Thesis. Rio de Janeiro (Brazil): Federal University of Rio de Janeiro, Civil Engineering Department, COPPE/UFRJ [in Portuguese].

Venuti, F., \& Reggio, A. (2018). Mitigation of human-induced vertical vibrations of footbridges through crowd flow control. Structural Control and Health Monitoring, 25(12), 1-16. https://doi.org/10.1002/stc.2266

Wang, J., \& Chen, J. (2017). A comparative study on different walking load models. Structural Engineering and Mechanics, 63(6), 847-856. https://doi.org/10.12989/sem.2017.63.6.847

Willford, M. and Young, P. (2006). A Design Guide for Footfall Induced Vibration of Structures. Concrete Centre: Surry, UK.

Yang, X. Bin, Jin, X. Q., Du, Z. M., Fan, B., \& Chai, X. F. (2011). Evaluation of four control strategies for building VAV air-conditioning systems. Energy and Buildings, 43(2-3), 414-422. https://doi.org/10.1016/j.enbuild.2010.10.004

Yao, S., Wright, J. R., Pavic, A., \& Reynolds, P. (2002). Forces generated when bouncing or jumping on a flexible structure. In: Proceedings of the International Conference on Noise and Vibration, 2, 563-572, Leuven, Belgium, 16-18 September.

Zhang, S., Xu, L., \& Qin, J. (2017). Vibration of lightweight steel floor systems with occupants: Modelling, formulation and dynamic properties. Engineering Structures, 147, 652-665. https://doi.org/10.1016/j.engstruct.2017.06.008 
Živanović, S. (2015). Modelling Human Actions on Lightweight Structures: Experimental and Numerical Developments. EVACES'15, 6th International Conference on Experimental Vibration Analysis for Civil Engineering. MATEC Web Conf. 2015, 24, 01005, doi:10.1051/matecconf/20152401005.

Živanović, S., \& Pavić, A. (2009). Probabilistic Modeling of Walking Excitation for Building Floors. Journal of Performance of Constructed Facilities, 23(3), 132-143. https://doi.org/10.1061/(ASCE)CF.1943-5509.0000005

Živanović, S., Pavic, A., \& Racic, V. (2012). Towards Modelling In-Service Pedestrian Loading of Floor Structures. In Conference Proceedings of the Society for Experimental Mechanics Series (Vol. 1, pp. 85-94). https://doi.org/10.1007/978-1-4614-2413-0_9

Živanović, S., Pavic, A., \& Reynolds, P. (2007). Probability-based prediction of multi-mode vibration response to walking excitation. Engineering Structures, 29(6), 942-954. https://doi.org/10.1016/j.engstruct.2006.07.004 


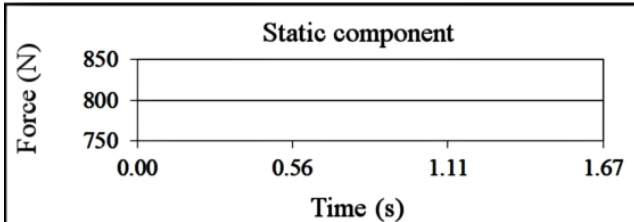

(a)

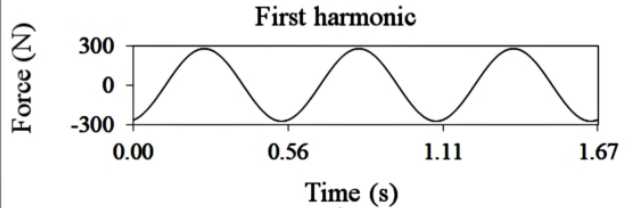

(b)

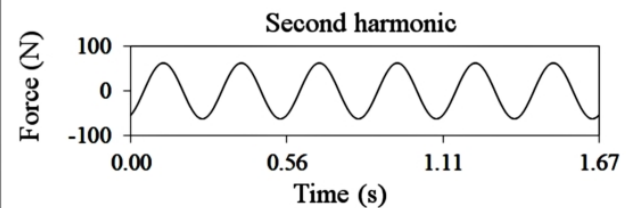

(c)

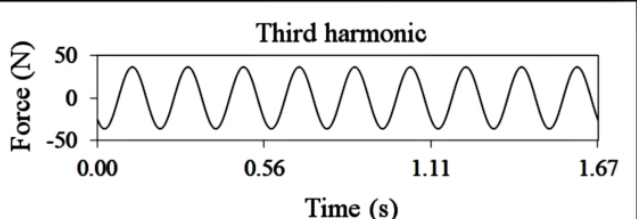

(d)

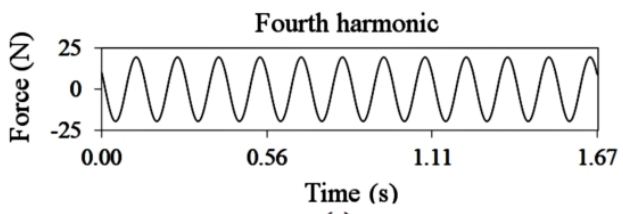

(e)

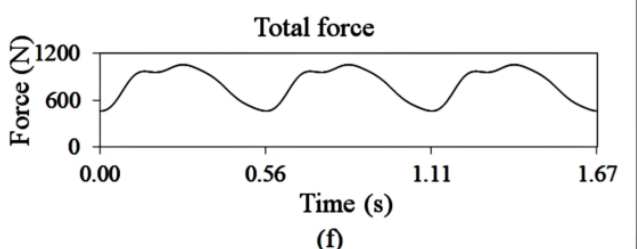

(f)

Figure 1. The first four harmonics and the total walking force (sum of harmonics), modelled by the Fourier series WFM, with walking frequency of $1.8 \mathrm{~Hz}$, person's weight of $800 \mathrm{~N}$, and phase angles $\varphi 1=0 ; \varphi 2=\varphi 3$ $=\varphi 4=\pi / 2$. DLFs are based on CSTR 43 (Pavic and Willford, 2005).

$149 \times 88 \mathrm{~mm}(600 \times 600 \mathrm{DPI})$ 


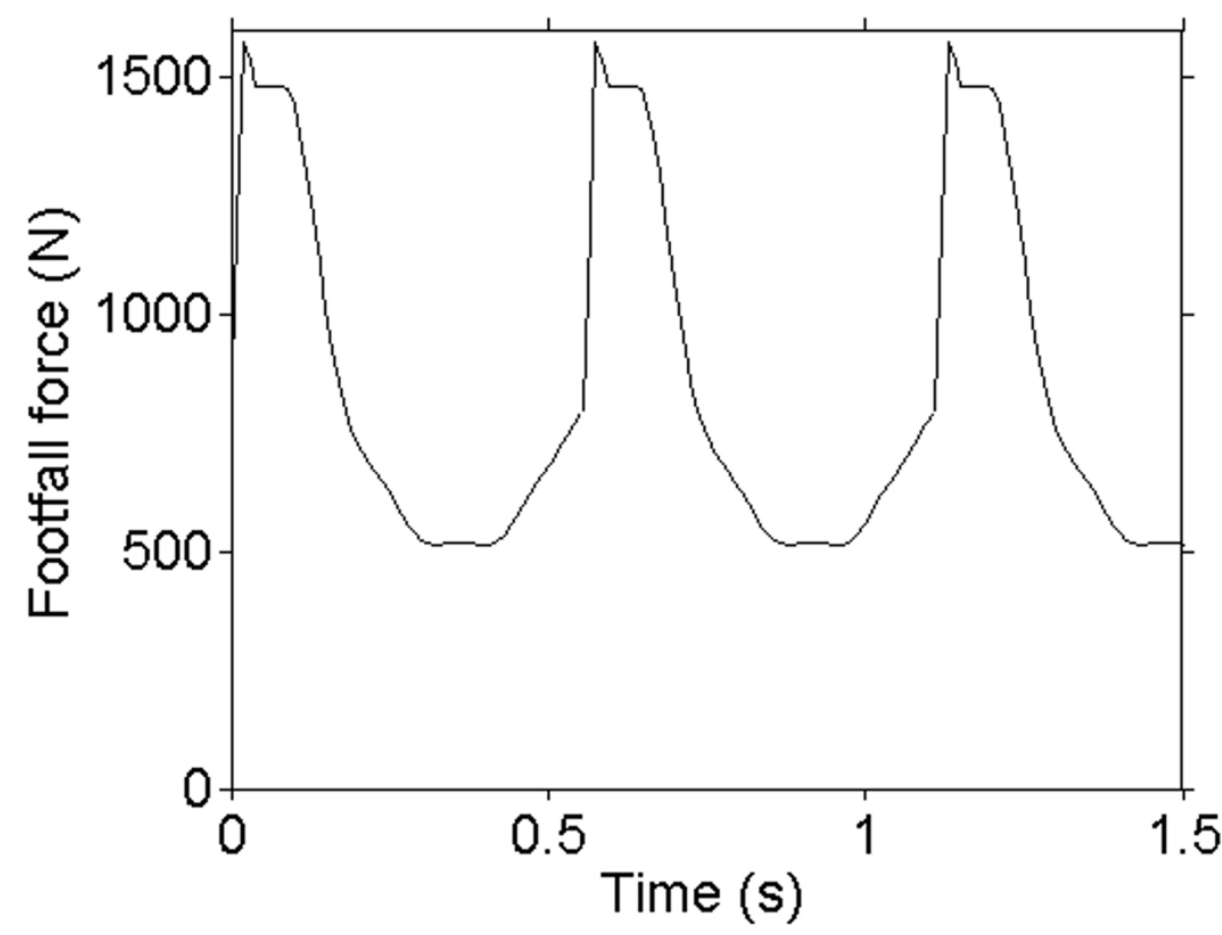

Figure 2. Adaptation of the Fourier Series WFM made by Varela (2004) to represent heel impact forces (walking frequency of $1.8 \mathrm{~Hz}$; four harmonics; person's weight of $800 \mathrm{~N}$; DLFs: $a 1=0.5, a 2=0.2, a 3=$ 0.1 , a4 = 0.05; and phase angles: $\varphi 1=0, \varphi 2=\pi / 2, \varphi 3=\pi, \varphi 4=3 \pi / 2$ ).

$80 \times 59 \mathrm{~mm}(600 \times 600 \mathrm{DPI})$ 


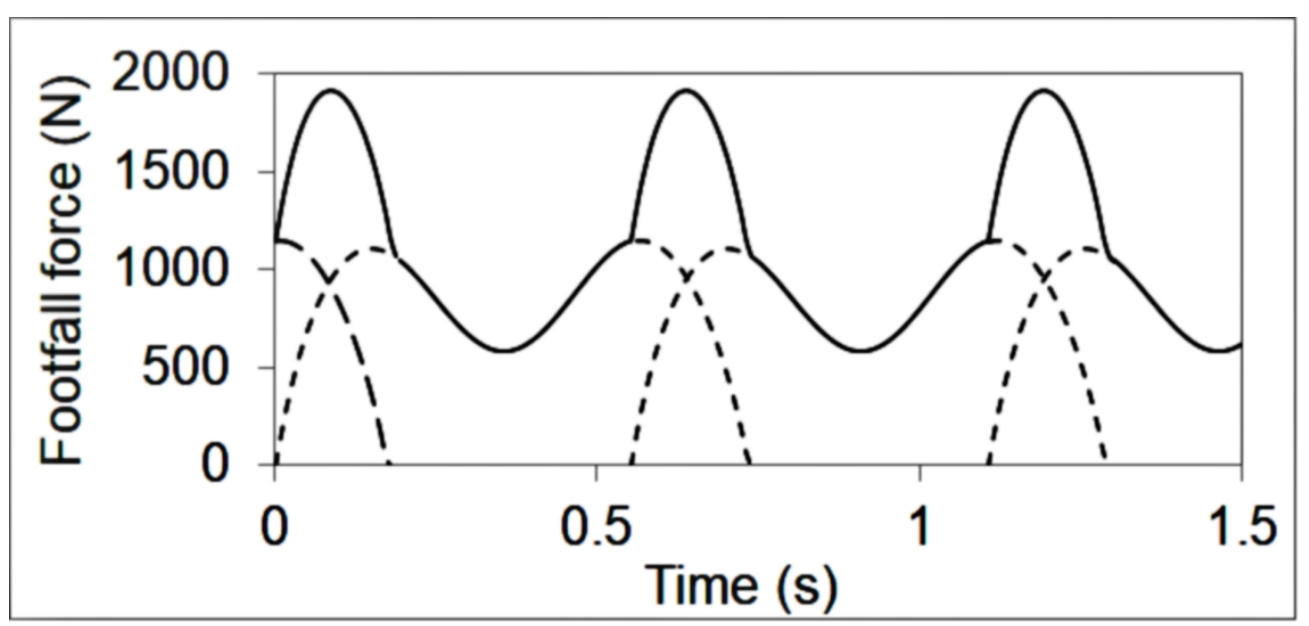

Figure 3. Time histories of force magnitudes from successive footsteps (individually shown) at walking frequency of $1.8 \mathrm{~Hz}$ and person's weight of $800 \mathrm{~N}$, according to HiVoSS (RFCS, 2007). The force signal of the sum of the footfall forces during the double stance is also shown.

$$
80 \times 37 \mathrm{~mm}(600 \times 600 \mathrm{DPI})
$$




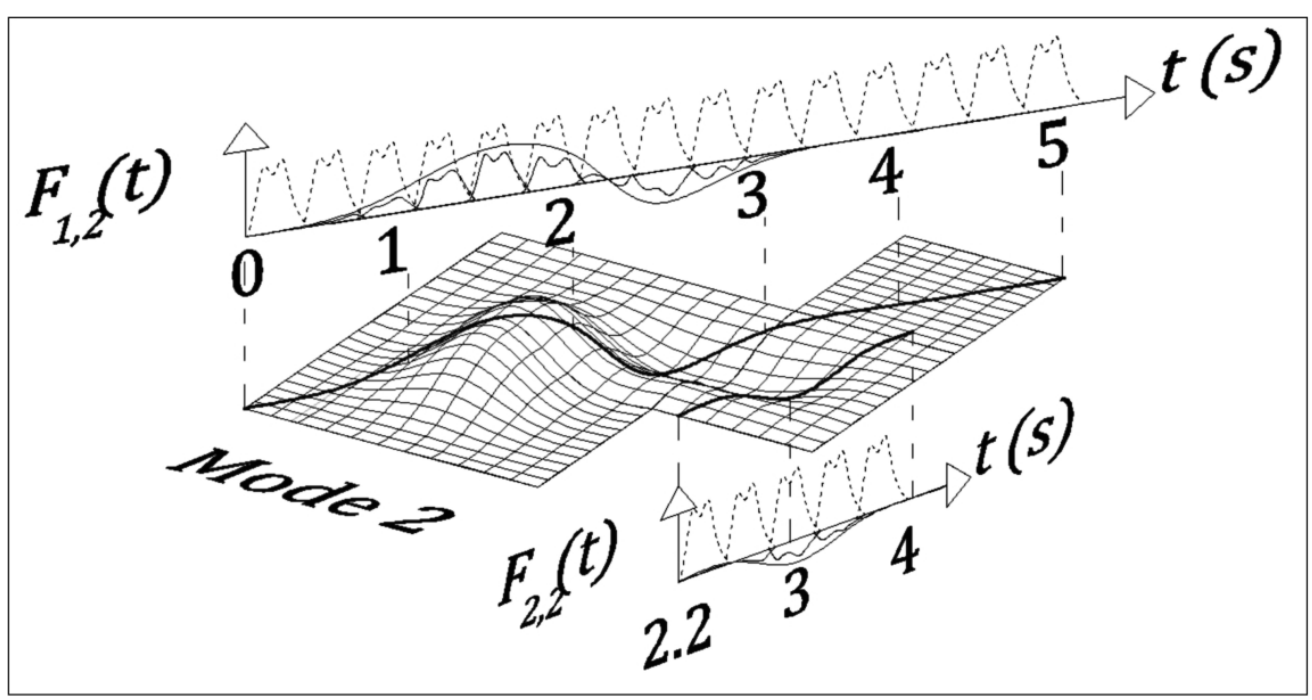

Figure 4. Modal walking forces of two occupants in an office, according to Shahabpoor et al. (2017a).

$119 \times 62 \mathrm{~mm}(600 \times 600 \mathrm{DPI})$ 


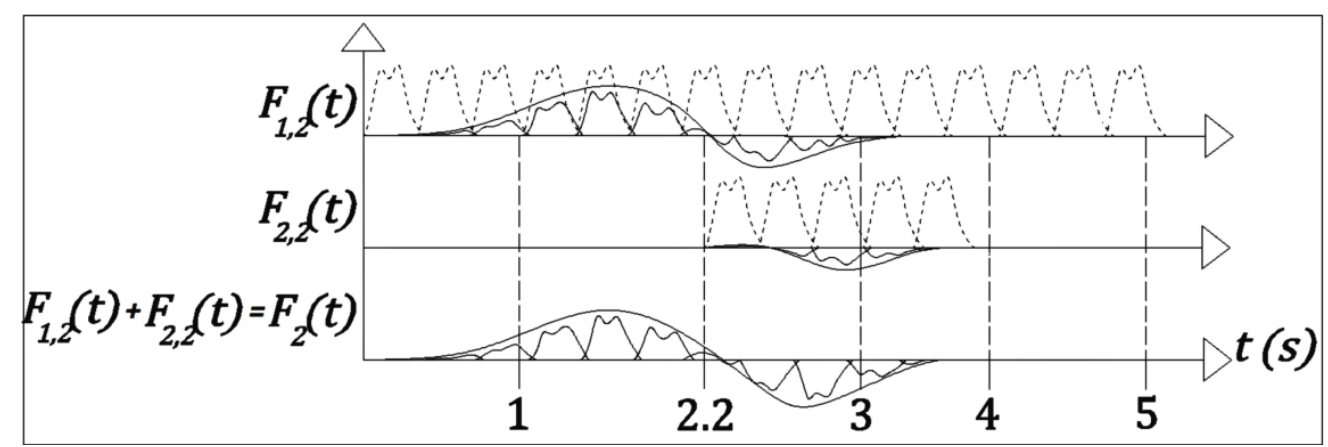

Figure 5. Modal walking forces of occupant $1, F 1,2(t)$ and occupant $2, F 2,2(t)$, summed up to yield the total modal walking force exciting mode $2, \mathrm{~F} 2(\mathrm{t})$, based on Shahabpoor et al. (2017a).

$119 \times 39 \mathrm{~mm}(600 \times 600 \mathrm{DPI})$ 


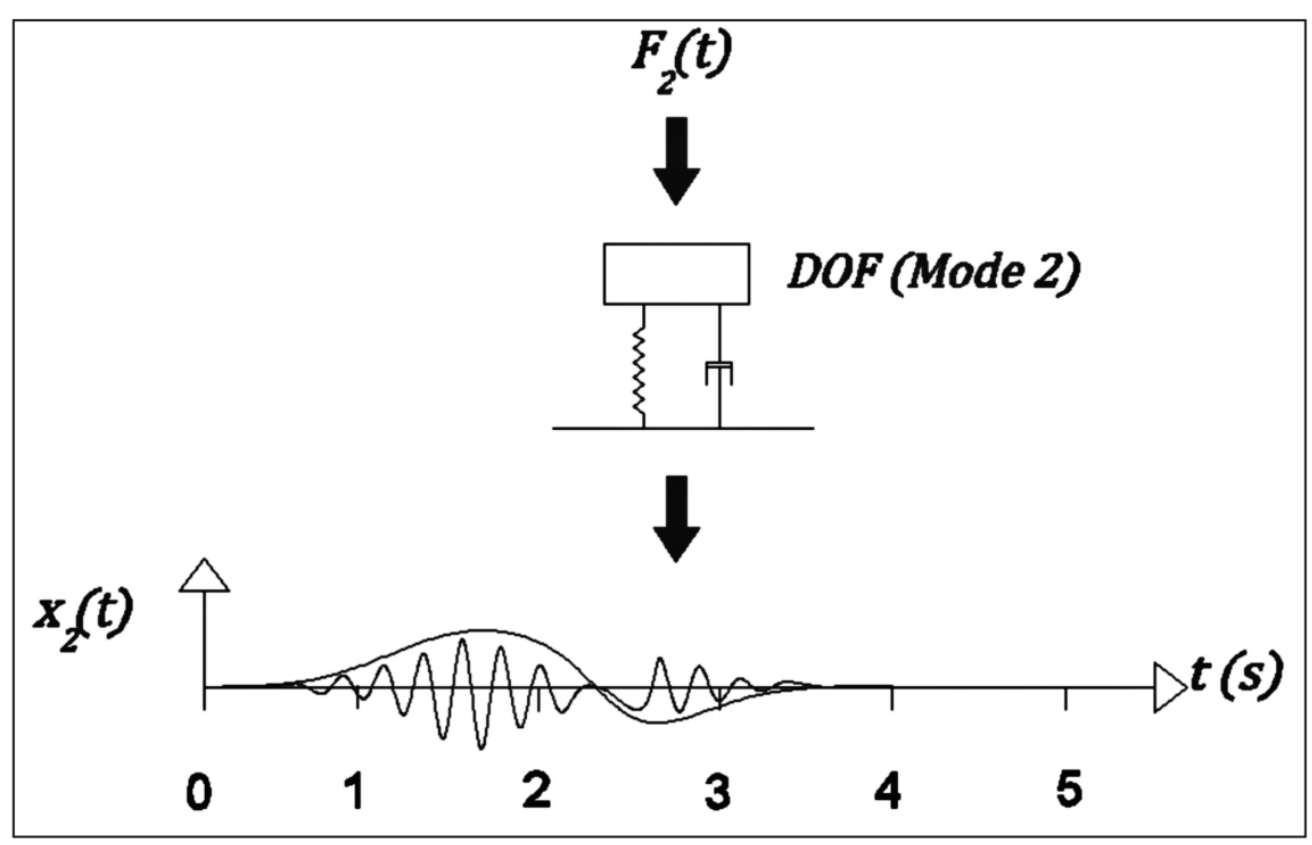

Figure 6. Modal floor response scaled by the mode shape amplitudes to yield the physical floor responses felt by an occupant, based on Shahabpoor et al. (2017a).

$80 \times 50 \mathrm{~mm}(600 \times 600 \mathrm{DPI})$ 


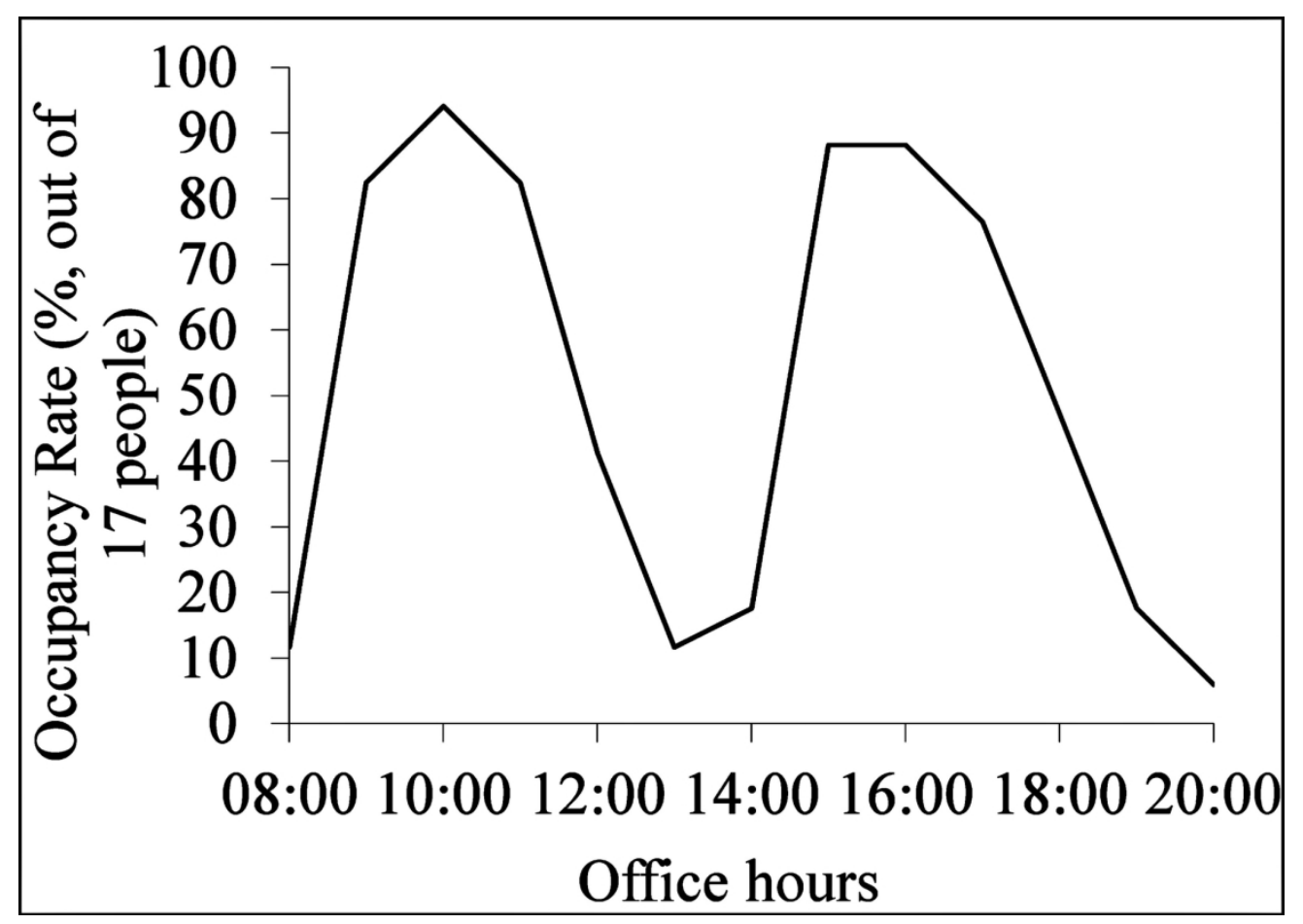

Figure 7. Rate of occupancy during working hours based on Yang et al. (2011). $80 \times 56 \mathrm{~mm}(600 \times 600 \mathrm{DPI})$ 


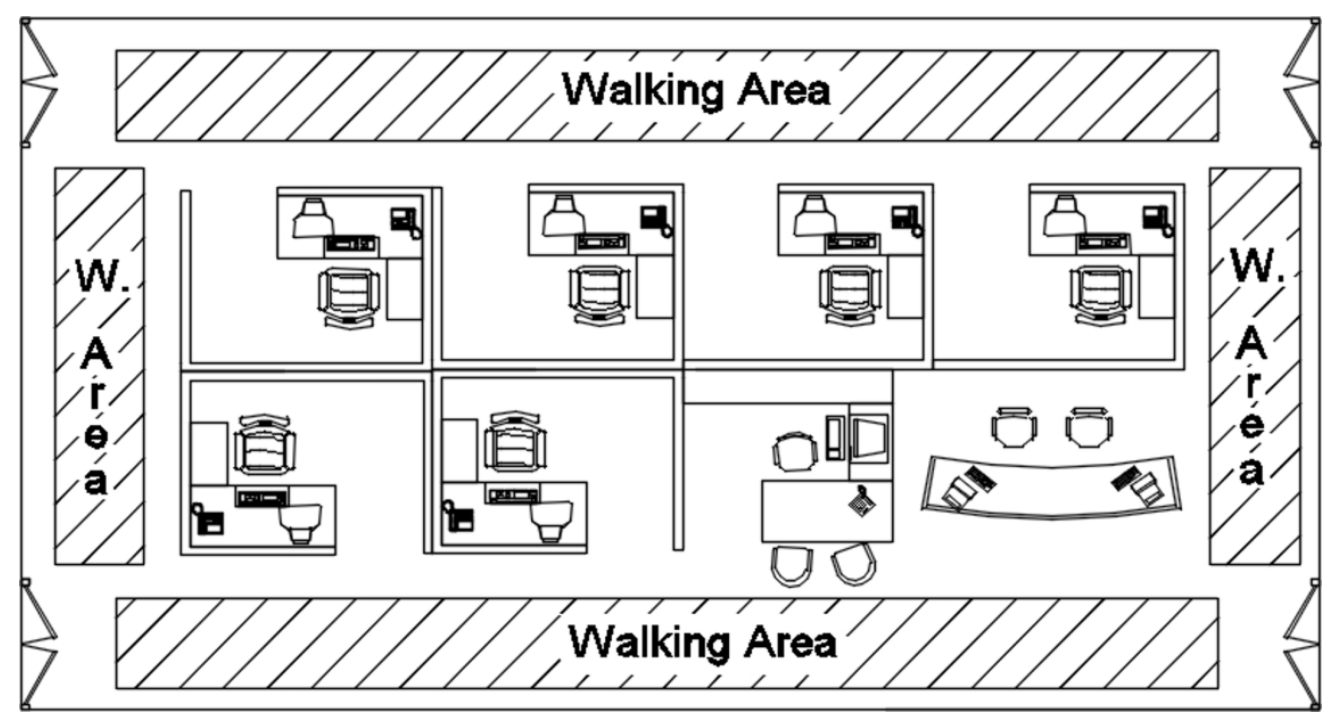

Figure 8. Office floor layout type 1.

$80 \times 42 \mathrm{~mm}(600 \times 600 \mathrm{DPI})$ 


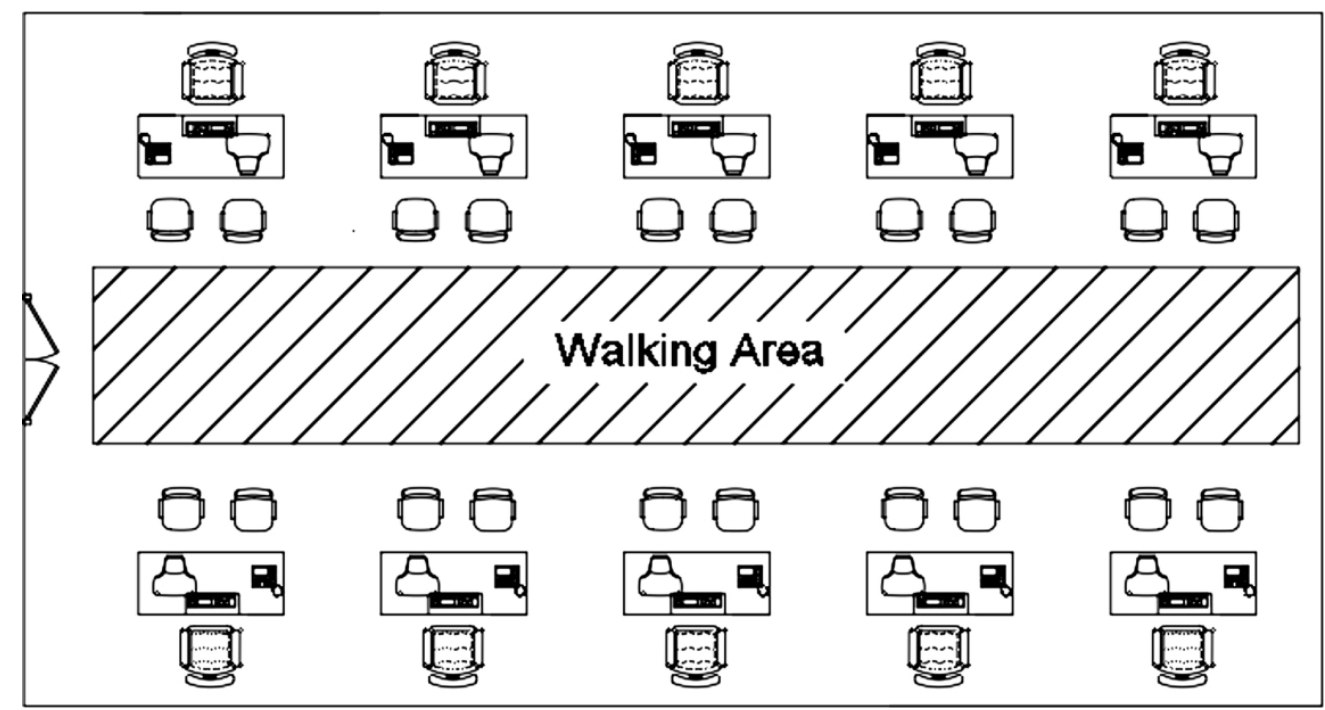

Figure 9. Office floor layout type 2.

$79 \times 42 \mathrm{~mm}(600 \times 600 \mathrm{DPI})$ 


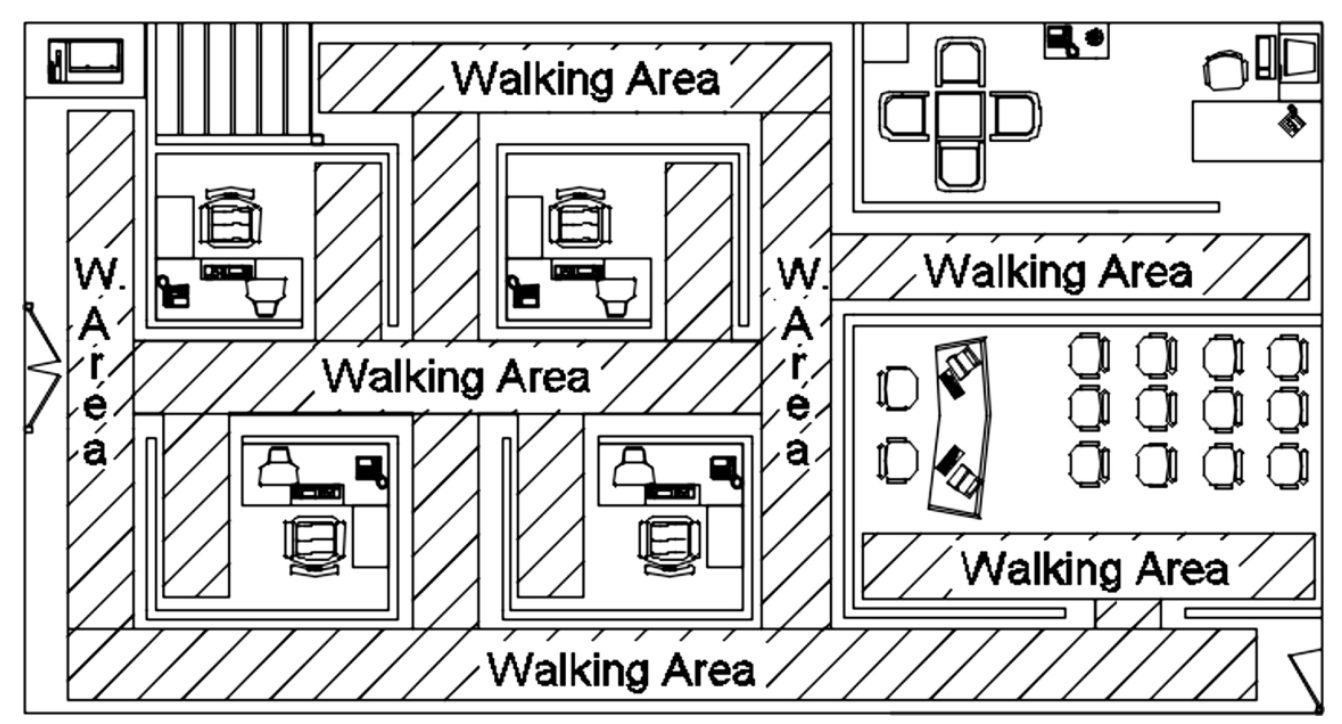

Figure 10. Office floor layout type 3.

$80 \times 42 \mathrm{~mm}(600 \times 600 \mathrm{DPI})$ 
Table 1. Case studies of excessive walking-induced floor vibrations.

Fund. nat. freq.: $6.5 \mathrm{~Hz} \quad$ Reinforced concrete. Damping ratio: not available. (Battista, 2001 apud Varela, 2004)
Reinforced concrete.

Damping ratio: $4.20 \%$ (Cantieni and Biro, 2005)

Fund. nat. freq.: $4.70 \mathrm{~Hz} \quad$ Steel-concrete composite. Damping ratio: not available.

(Hanagan, 2005)

Fund. nat. freq.: $5.25 \mathrm{~Hz} \quad$ Lightweight concrete. Damping ratio: not available.

(Setareh et al., 2006)

Fund. nat. freq.: $4.38 \mathrm{~Hz} \quad$ Steel-concrete composite. Damping ratio: not available.

(Setareh et al., 2006)

Fund. nat. freq.: $5.20 \mathrm{~Hz} \quad$ Steel-concrete composite. Damping ratio: $1.80 \%$. (Pavic et al., 2007)

Fund. nat. freq.: $4.44 \mathrm{~Hz}$ Damping ratio: $1.40 \%$ (Smith et al., 2009)

\section{Floor description}

-Walking path: not available.

- Layout: computer workstations; some walls present in one of the three bays. - Floor panel dimensions: 8.6 x $25.8 \mathrm{~m}$ (three squared bays of $8.6 \times 8.6 \mathrm{~m}$ ).

-Walking path: not available.

- Layout: not available.

- Floor panel dimensions: 6.25 x $8.8 \mathrm{~m}$

-Walking path: not available.

- Layout: lightweight partitions.

- Floor panel dimensions: only the span length of $7 \mathrm{~m}$ (approx.) was informed.

-Walking path: office central area.

- Layout: open cubicle style; paperless; some office partitions.

- Floor panel dimensions: 9.1 x $14.3 \mathrm{~m}$.

-Walking path: not available.

- Layout: raised floor; lightweight partitions.

- Floor panel dimensions: 12.5 x 9.15 $\mathrm{m}$.

-Walking path: lateral corridors.

- Layout: raised floor; open-plan; some lightweight partitions.

- Floor panel dimensions: 12.2 x 9.15 $\mathrm{m}$.

-Walking path: not available.

- Layout: open-plan; fully furnished.

- Floor panel dimensions: 11.25 x 6.75 $\mathrm{m}$.

Steel-concrete composite. -Walking path: not available.

- Layout: not available.

- Floor panel dimensions: only span in one direction was informed $(16.7 \mathrm{~m})$. 
Table 1. Case studies of excessive walking-induced floor vibrations (continuation).

\begin{tabular}{|c|c|c|c|}
\hline Case \# & Dynamic properties & Floor System & Floor description \\
\hline 9 & $\begin{array}{l}\text { Fund. nat. freq.: } 6.40 \mathrm{~Hz} \\
\text { Damping ratio: } 3 \% . \\
\text { (Díaz and Reynolds, } \\
\text { 2010) }\end{array}$ & Steel-concrete composite. & $\begin{array}{l}\text {-Walking path: lateral corridors. } \\
\text { - Layout: open-plan; no partitions; } \\
\text { paperless. } \\
\text { - Floor panel dimensions: not available } \\
\text { (only total floor area of } 24 \text { x } 72 \mathrm{~m} \text { was } \\
\text { informed). }\end{array}$ \\
\hline 10 & $\begin{array}{l}\text { Fund. nat. freq.: } 5.60 \mathrm{~Hz} \\
\text { Damping ratio: } 2 \% . \\
\text { (Lindenberg and } \\
\text { Fraczek, 2013) }\end{array}$ & Precast concrete. & $\begin{array}{l}\text {-Walking path: not available. } \\
\text { - Layout: bare floor. } \\
\text { - Floor panel dimensions: bay of } 15.25 \\
\text { x } 14 \text { m. }\end{array}$ \\
\hline 11 & $\begin{array}{l}\text { Fund. nat. freq.: } 6.20 \mathrm{~Hz} \\
\text { Damping ratio: } 2.5-3 \% \text {. } \\
\text { (Nguyen et al., 2014) }\end{array}$ & Steel-concrete composite. & $\begin{array}{l}\text {-Walking path: two corridors crossing } \\
\text { centre bay. } \\
\text { - Layout: not available. } \\
\text { - Floor panel dimensions: not available. }\end{array}$ \\
\hline 12 & $\begin{array}{l}\text { Fund. nat. freq.: } 5.24 \mathrm{~Hz} \\
\text { Damping ratio: } 3.16 \% \\
\text { (Muhammad and } \\
\text { Reynolds, 2019) }\end{array}$ & Steel-concrete composite. & $\begin{array}{l}\text {-Walking path: path crossing three } \\
\text { panels adjacent to building perimeter. } \\
\text { - Layout: open-plan. } \\
\text { - Floor panel dimensions: } 13 \text { x } 9 \mathrm{~m} \text {. }\end{array}$ \\
\hline 13 & $\begin{array}{l}\text { Fund. nat. freq.: } 4.92 \mathrm{~Hz} \\
\text { Damping ratio: } 0.66 \% \\
\text { (Muhammad and } \\
\text { Reynolds, 2019) }\end{array}$ & Steel-concrete composite. & $\begin{array}{l}\text {-Walking path: path crossing five panels } \\
\text { adjacent to building perimeter. } \\
\text { - Layout: not informed. } \\
\text { - Floor panel dimensions: } 15 \text { × } 6.25 \mathrm{~m} \text {. }\end{array}$ \\
\hline 14 & $\begin{array}{l}\text { Fund. nat. freq.: } 6.56 \mathrm{~Hz} \\
\text { Damping ratio: } 1.0 \% \\
\text { (Muhammad and } \\
\text { Reynolds, 2019) }\end{array}$ & Steel-concrete composite. & $\begin{array}{l}\text {-Walking path: not available. } \\
\text { - Layout: fully furnished; multipurpose } \\
\text { building. } \\
\text { - Floor panel dimensions: } 9.75 \text { x } 6.1 \mathrm{~m} \text {. }\end{array}$ \\
\hline 15 & $\begin{array}{l}\text { Fund. nat. freq.: bays } \\
\text { with } f 1 \text { within } 4.5-6.5 \\
\text { Hz. } \\
\text { Damping ratio: not } \\
\text { available. } \\
\text { (Wong and Wesolowsky, } \\
\text { 2019) }\end{array}$ & Steel-concrete composite. & $\begin{array}{l}\text {-Walking path: not available. } \\
\text { - Layout: open-plan. } \\
\text { - Floor panel dimensions: } 9.15 \text { x } 9.15 \\
\text { m. }\end{array}$ \\
\hline 16 & $\begin{array}{l}\text { Fund. nat. freq.: } 4.0 \mathrm{~Hz} \text {. } \\
\text { Damping ratio: not } \\
\text { available. } \\
\text { (Wong and Wesolowsky, } \\
\text { 2019) }\end{array}$ & Steel-concrete composite. & $\begin{array}{l}\text {-Walking path: not available. } \\
\text { - Layout: not available. } \\
\text { - Floor panel dimensions: } 12.2 \text { x } 9.15 \\
\text { m. }\end{array}$ \\
\hline
\end{tabular}


Table 1. Case studies of excessive walking-induced floor vibrations (continuation).

\begin{tabular}{|c|c|c|c|}
\hline Case \# & Dynamic properties & Floor System & Floor description \\
\hline 17 & $\begin{array}{l}\text { Fund. nat. freq.: bays } \\
\text { with } f 1 \text { within } 5.0-6.3 \\
\text { Hz. } \\
\text { Damping ratio: not } \\
\text { available. } \\
\text { (Wong and Wesolowsky, } \\
2019 \text { ) }\end{array}$ & Steel-concrete composite. & $\begin{array}{l}\text {-Walking path: not available. } \\
\text { - Layout: not available. } \\
\text { - Floor panel dimensions: } 9.15 \text { x } 9.15 \\
\text { m. }\end{array}$ \\
\hline 18 & $\begin{array}{l}\text { Fund. nat. freq.: bays } \\
\text { with } f 1 \text { within } 5.7-6.3 \\
\text { Hz. } \\
\text { Damping ratio: not } \\
\text { available. } \\
\text { (Wong and Wesolowsky, } \\
\text { 2019) }\end{array}$ & Reinforced concrete. & $\begin{array}{l}\text {-Walking path: grid-like pattern around } \\
\text { the centre of the floor. } \\
\text { - Layout: not available. } \\
\text { - Floor panel dimensions: } 8 \text { × } 8 \mathrm{~m} \text {. }\end{array}$ \\
\hline
\end{tabular}

